\title{
Nova Interface do Jogo “Ludo Educativo Primeiros Passos” para Crianças com Transtorno do Espectro Autista
}

\author{
New Interface of the Game "Ludo Educativo Primeiros Passos" for Children with Autistic \\ Spectrum Disorder
}

\author{
Gabriela Mees de Souza \\ Universidade do Planalto Catarinense \\ gabimees@hotmail.com
}

\author{
Giovani Letti \\ Universidade do Planalto Catarinense \\ giovaniletti@gmail.com
}

\author{
Vivian Fátima de Oliveira \\ Universidade do Planalto Catarinense \\ vivianfatima@yahoo.com.br
}

\author{
Madalena Pereira da Silva \\ Universidade do Planalto Catarinense \\ madalena@uniplaclages.edu.br
}

\author{
Tania Mara Zancanaro Pieczkowski \\ Universidade Comunitária da Região de Chapecó \\ taniazp@unochapeco.edu.br
}

\begin{abstract}
Resumo
A Informática na Educação contribui com a criação de tecnologias assistivas, softwares educacionais e jogos educativos para a aprendizagem significativa dos alunos. Contudo, considerando as particularidades de cada necessidade especial, a grande maioria dos materiais não é aplicável para a Educação Especial, mas pode ser adaptada para tal propósito, desde que se adotem diretrizes válidas, pertinentes ao tipo de necessidade especial, no desenvolvimento dos recursos pedagógicos. Neste artigo é proposta a reformulação da interface do jogo "Ludo Educativo Primeiros Passos” para a alfabetização de crianças com Transtorno de Espectro Autista (TEA). Na reformulação foi adotada a abordagem da User Experience (UX), que dispõe de um arcabouço para desenvolver softwares orientados às necessidades dos usuários. A metodologia consistiu da busca sistemática sobre diretrizes para projetar recursos educacionais, com acessibilidade da Web Cognitiva; coleta de dados com mães de crianças com TEA; projeto e desenvolvimento da nova interface do jogo. E por fim, usando a pesquisa experimental foram realizados os testes de usabilidade, com crianças com TEA, para avaliar a interface do jogo, antes e após a reformulação da mesma. Os resultados e discussões demonstram que a nova interface é promissora, pois além de ser bem aceita pelas crianças, possibilitou a realização das tarefas com êxito.
\end{abstract}

Palavras-Chave: Educação; Technology; Ludo Educativo; Transtorno do Espectro Autista; User Experience.

\begin{abstract}
Informatics in Education contributes to the creation of assistive technologies, educational software and educational games for meaningful student learning. However, given the particularities of each special need, the vast majority of materials are not applicable to Special Education, but can be adapted for this purpose, provided that valid guidelines, pertinent to the type of special need, are adopted in the development of pedagogical resources. In this article it is proposed the redesign of the interface of the game "Ludo Educativo Primeriros Passos" for the literacy of children with Autistic Spectrum Disorder (TEA). In the redesign, the User Experience (UX) approach was adopted, which has a framework to develop software oriented to users' needs. The methodology consisted of the systematic search on guidelines for designing educational resources, with Cognitive Web accessibility; data collection with mothers of children with ASD; design and development of the new game interface. Finally, using the experimental research, we performed the usability tests, with children with ASD, to evaluate the game interface before and after the game redesign. The results and discussions show that the new interface is promising, as well as being well accepted by the children, enabled the successful accomplishment of the tasks.
\end{abstract}

Keywords: Education; Informatics; Ludo Educativo; Autism Spectrum Disorder; User Experience.

Cite as: Souza, G. M. de, Letti, G., Oliveira, V. F. de, Silva, M. P. da \& Pieczkowski, T. M. Z (2019). New Interface of the Game "Ludo Educativo Primeiros Passos" for Children with Autistic Spectrum Disorder (Nova Interface do Jogo "Ludo Educativo Primeiros Passos" para Crianças com Transtorno do Espectro Autista). Brazilian Journal of Computers in Education (Revista Brasileira de Informática na Educação RBIE), 27(3), 285-309. DOI: 10.5753/RBIE.2019.27.03.285 


\section{Introdução}

O Transtorno do Espectro Autista (TEA) é um distúrbio do neurodesenvolvimento cujos sintomas se manifestam em condição espectral em três níveis de gravidade relacionados a "déficits persistentes na comunicação social e na interação social em múltiplos contextos" e "padrões restritos e repetitivos de comportamento, interesses ou atividades" (APA, 2014, p. 50). Os déficits apresentados na comunicação social e a inflexibilidade de comportamentos restritos e repetitivos podem comprometer em maior ou menor grau a capacidade adaptativa e aprendizagem das crianças autistas (APA, 2014, p. 50).

Segundo as Diretrizes de Atenção à Reabilitação de Pessoa com Transtornos do Espectro do Autismo, mais recentemente, TEA é o termo usado para se referir a uma parte dos Transtornos Globais do Desenvolvimento (TGD): o Autismo, a Síndrome de Asperger e o Transtorno Global do Desenvolvimento sem outra especificação (não incluindo Síndrome de Rett e Transtorno Desintegrativo da Infância).

Conforme a Política Nacional de Educação Especial, na Perspectiva da Educação Inclusiva, entende-se como sujeitos com TGD, os alunos [...] "que apresentam alterações qualitativas das interações sociais recíprocas e na comunicação, um repertório de interesses e atividades restrito, estereotipado e repetitivo. Incluem-se nesse grupo alunos com autismo, síndrome do espectro do autismo e psicose infantil.” (Brasil, 2008, p. 15).

As ações de intervenção junto à criança com TEA em diferentes contextos (familiar, escolar, social e profissional na vida adulta) constituem-se em um importante modulador de prognóstico, portanto, é primordial adotar estratégias para nortear a trajetória de desenvolvimento de uma criança com TEA. Segundo Faria et al. (2018, p. 355), “A escola deverá estimular, além de habilidades de aprendizagem, habilidades de reciprocidade sócio emocional, comunicação social, tanto verbal como não verbal, habilidades sociais, interesses variados, rotinas padronizadas de vida na escola, oportunizar ambientes planejados para evitar e/ou diminuir a ocorrência de problemas de comportamento como estereotipias corporais e gestuais, comportamentos agressivos e autoagressivos, hiper ou hiporreatividade a estímulos sensoriais, dentre outros”.

Na concepção de Rodriguez e Pico (2016) as pessoas com o distúrbio têm diferentes padrões de funcionamento cognitivo, tornando seus estilos de aprendizagem diferentes e exigindo abordagens específicas. Entre elas, e por causa de sua repercussão para facilitar esse aprendizado, o uso da tecnologia é especialmente relevante. O rápido desenvolvimento de avanços nesta área tem gerado enorme interesse no campo de intervenção e apoio e tem sido um desafio transformar as práticas educacionais adaptáveis às novas exigências e demandas (Rodriguez \& Pico, 2016).

Os jogos (computacionais ou desprovidos de computadores) têm ótima aceitação por crianças com TEA, em especial para os “nativos digitais” (Prensky, 2001). A aceitação de jogo desprovido de computador foi evidenciada no relato de experiência da inclusão escolar de um aluno com autismo, em diferentes tempos de escuta, intervenção e aprendizagens, por Brande e Zanfelice (2012, p. 52), “[...] os jogos podiam ser 'ativados' pela professora. Isso acontecia quando percebia que ele não estava se concentrando na realização das atividades e precisava de rapidez e criatividade suficiente para chamar sua atenção: bastava questioná-lo sobre algum fato engraçado, ou inventar uma história; fazer relação com personagens de desenhos animados, perguntar se ele comeria pipoca no final da tarde, acompanhada de seu refrigerante preferido, ou convidá-lo para cantar músicas conhecidas por ele”.

Na pesquisa apresentada por Rodriguez e Pico (2016) é feito um mapeamento das Tecnologias da Informação e Comunicação (TIC) existentes, utilizadas no diagnóstico, 
educação, tratamento e assistência às pessoas com TEA (softwares, plataformas web, robótica, aplicações móveis, recursos midiáticos, entre outros). As tecnologias foram desenvolvidas para suportar as necessidades, fornecendo ferramentas nas diferentes áreas: inserção social, comunicação, aprendizagem, cognição e autonomia (Rodriguez \& Pico, 2016). Em adição, Nicolás (2004, p. 3) descreve que "Las TIC pueden ser para los autistas lo que la lengua de signos para los sordos” (adaptado de M. Dekker, defensor da cultura autista emergente).

Conforme posto na literatura (Avila, Passerino \& Tarouco, 2013; Nicolás, 2004; Rodriguez \& Pico, 2016) é inegável que as TIC podem ser usadas como recursos facilitadores nas interações sociais, comunicações, entretenimento e ensino-aprendizagem das pessoas com TEA. Contudo, não basta apenas disponibilizar tais recursos em diferentes ambientes e dispositivos, pois "cabe salientar que a idealização de sistemas requer cuidados relacionados à interação usuário/interface” (neste caso qualquer pessoa diagnosticada com TEA). Os autores destacam, ainda, o desafio existente no planejamento de um sistema de comunicação alternativo que, além de ser multi plataforma (disponível e acessível de qualquer dispositivo) deve ser "capaz de atender as necessidades de comunicação de um público tão peculiar como os indivíduos afetados pelo TEA” (Avila, Passerino \& Tarouco, 2013, p. 118). Portanto, faz-se saber que o projeto de ergonomia e usabilidade do sistema (software, aplicativo, jogo ou qualquer recurso pedagógico provido de interface gráfica) é primordial para a aceitação da tecnologia pelo autista.

No percurso desta pesquisa, alguns fatores restritivos foram evidenciados na literatura, a saber. Nielsen (2000, p. 310) descreve que "as deficiências cognitivas não são foco em pesquisas de interfaces em relação a usuários com deficiências físicas, sendo assim as diretrizes para a elaboração do projeto de interface do software/jogo, ainda não são bem definidas”. Em adição, a pesquisa desenvolvida por Pagani Britto e Pizzolato (2018) evidencia que 84\% dos desenvolvedores de software não consideram ou consideram parcialmente pessoas com deficiência cognitiva ou neural em projetos. Por outro lado, $75 \%$ dos que não consideram, ou, o fazem porque desconhecem as características destas deficiências para aplicar em seus projetos. Outros 54\% dizem que na empresa em que atuam esses usuários não fazem parte do seu público alvo e por isso não são levados em consideração. Por último, Faria et al. (2018) descrevem que no cenário nacional brasileiro, ainda são reportados insucessos nas ações de inclusão escolar junto aos alunos com TEA.

Para Bernardino (2015) é pela escrita e pela alfabetização que a criança com TEA começa a ter possibilidades de comunicação com o outro. É através do jogo, um recurso lúdico, que a criança "desenvolva sua imaginação, sua capacidade de sistematizar e abstrair, sua capacidade de interagir socialmente, logo, permitindo que o sujeito desenvolva seu espírito construtivo" (Francisco \& Silva, 2015, 286). Nessa perspectiva, visando contribuir, com a alfabetização de crianças com TEA, de forma lúdica, optou-se pelo Ludo Educativo.

O Ludo Educativo é um portal que contém diversos jogos de aprendizagem para motivar e divertir as crianças de forma que elas aprendam brincando, e um deles é o Ludo Educativo Primeiros Passos. Tal jogo tem sido referenciado como uma alternativa viável para auxiliar na alfabetização de crianças (Mallmann, 2017), contudo, há que se considerar que o foco do mesmo é na alfabetização de crianças que não possuem transtorno do neurodesenvolvimento, como ocorre com crianças com TEA.

Este trabalho tem por objetivo analisar e adaptar a interface gráfica do jogo Ludo Educativo Primeiros Passos, bem como realizar testes de usabilidade do jogo com crianças que apresentam TEA.

\section{Do Estado da Arte à Fundamentação Teórica}


Esta seção apresenta os softwares educacionais que podem ser usados por crianças com TEA. As recomendações e diretrizes para construção de softwares educacionais inclusivos e um embasamento sobre User Experience (UX), abordagem adotada para criar softwares orientados às necessidades dos usuários.

\subsection{Pesquisa sobre os softwares educacionais à autistas}

Visando evidenciar a contribuição do artigo frente ao estado-da-arte dos principais veículos de publicação da área, foi realizadas buscas sistemáticas no portal de periódicos da CAPES, com os termos "autismo" e "tecnologia", sendo retornados 257 resultados e com os termos "autismo" e software educacional, com 25 resultados. Após a leitura dos resumos observou-se a carência de softwares educacionais para alfabetização de autistas, pois dos 282 resultados, apenas cinco deles tem alguma relação com alfabetização ou comunicação alternativa com uso de tecnologias digitais. Ressalta-se que dos cinco artigos selecionados, quatro deles abordam o Sistema de Comunicação Alternativa para o Letramento de Pessoas com Autismo (SCALA). A carência de softwares educacionais para pessoas com TEA, já havia sido registrada na pesquisa apresentada por de Araújo, de Brito e Silva (2013).

O uso das tecnologias e recursos digitais é usado como sistema de Comunicação Aumentativa e Alternativa (CAA) orientado para crianças com autismo. Nessa perspectiva Avila, Passerino e Reategui (2012) propõem uma metodologia para a construção de um sistema de CAA focado no contexto de seus usuários, crianças com TEA não oralizadas. Para prover o design centrado no contexto do usuário a metodologia consistiu em dois processos distintos de avaliação sobre a ferramenta: - avaliações iniciais realizadas com uma criança com TEA e avaliações realizadas por um grupo de educadores que verificou a usabilidade do sistema, analisando sua interface. Os autores relatam que as avaliações levaram a um aperfeiçoamento do sistema, tendo por base as necessidades apresentadas pelos seus futuros usuários.

A pesquisa de Avila, Passerino e Tarouco (2013) apresenta o processo de construção e avaliação pelos quais passou o SCALA. Uma das autoras da pesquisa inspecionou, previamente, 10 tarefas que foram propostas no teste de usabilidade do sistema. Os testes de usabilidade foram realizados por quatro educadoras da educação especial atuantes em salas de recursos, com crianças com déficits de oralidade. Os resultados das avaliações são satisfatórios, contudo, indicaram para um conjunto de melhorias a serem implementadas na próxima versão do sistema. O SCALA, gradativamente, recebeu novas versões, com implementação de novos módulos, como é o caso do módulo de narrativas visuais para a construção de histórias nas plataformas web e android/tablet utilizado em outra pesquisa (de Souza Bittencourt \& Fumes 2017).

Os autores de Souza Bittencourt e Fumes (2017, p. 1481) utilizaram o SCALA como recurso de produção de narrativas e registro de dados nas pesquisas em educação. O estudo explorou o módulo de narrativas visuais com quatro participantes adultos, com TEA. De acordo com os autores, os resultados apontam que o SCALA é uma tecnologia assistiva que "permitiu conhecer as percepções dos participantes quanto aos professores, escola e amigos, seus interesses e dificuldades, experiências positivas e negativas e sentimentos quanto à interrupção do processo de escolarização".

Em Lindenmeyer et al. $(2016,47)$ são utilizados os softwares SCALA e ARASAAC como recursos pedagógicos, proporcionando aprendizado e desenvolvimento em uma criança com TEA, que chega a escola "com handicap expressivamente inferior à sua potência e condição de aprendizagem, apresentando limitação bem evidenciada no que se refere à sua linguagem oral (hipotonia orofacial), com comorbidade psíquica de 'imaturidade' e hipótese de espectro autista trazida à família por um dos pediatras que o menino consultou”. Para os autores, os recursos utilizados, alinhados as práticas pedagógicas, interações com os colegas e apoio da família, colaboraram para a comunicação alternativa, favorecendo a capacidade de comunicar-se, falar, opinar e atuar ativamente em ambientes onde está envolvido e em que vive. 
No estudo de Gonçalves, Picharillo e Pedrino (2017) é descrita a experiência de uso do software educativo Jclic, com vinte e duas crianças da educação infantil, sendo uma criança diagnosticada com autismo e outra com dificuldades de comunicação oral. Uma atividade de interação e comunicação foi proposta aos alunos. Os dados obtidos foram analisados de forma qualitativa tendo como base a observação e registro, seguindo a metodologia de relato de estudo de caso. Como resultados, os autores evidenciaram que todas as crianças conseguiram atingir o objetivo proposto e o software proporcionou a interação entre as mesmas, servindo como um recurso para potencializar o processo de ensino e de aprendizagem.

\subsection{Acessibilidade da Web Cognitiva}

Considerando que o Ludo é um jogo para Web, os web designers e desenvolvedores, geralmente, seguem as Diretrizes de Acessibilidade para Conteúdo Web (WCAG), com técnicas de produção de conteúdo acessíveis às pessoas com deficiência visual, auditiva ou motora (Ferraz \& Bechara, 2014). Embora essas técnicas abordem alguns aspectos relacionados à aprendizagem e cognição, para Pagani Britto e Pizzolato (2018, p. 104) ainda existem "poucas recomendações de acessibilidade que endereçam especificamente as Deficiências Cognitivas, Neuronais ou de Aprendizagem (DCNA)", ou seja, é preciso prover diretrizes para o desenvolvimento de aplicações com Acessibilidade Web Cognitiva. Nesse viés tanto a W3C (Seeman \& Cooper, 2018a, 2018b) quanto a WebAIM (2014) tem aplicado esforços na difusão do conhecimento sobre o tema.

A Acessibilidade Web Cognitiva provê uma documentação de base (Seeman \& Cooper, 2018a) para permitir que os pesquisadores (grupos de trabalho por tipo de deficiência, incluindo o autismo) possam evidenciar lacunas, sugerir técnicas e criar roteiros para o desenvolvimento de tecnologias Web com acessibilidade adequada às pessoas com dificuldades de aprendizagem e deficiências cognitivas.

A Acessibilidade Web Cognitiva para autistas, preocupa-se com os aspectos e condições que podem afetar as pessoas com DCNAs na realização de tarefas em websites relacionados ao estudo da memória; solução de problemas; atenção; leitura, compreensão linguística e verbal; compreensão matemática e compreensão visual. Para contemplar esses aspectos, os princípios de Acessibilidade Web Cognitiva são norteados pela simplicidade; consistência e clareza (Seeman \& Cooper, 2018a, 2018b). Na mesma direção, no projeto que originou o Guia de Acessibilidade de Interfaces Web focado em Aspectos do Autismo (GAIA), Britto (2016), é proposto um guia de recomendações para desenvolvimento de sites acessíveis a pessoas com Autismo. E por último, Dias (2003) aborda aspectos de usabilidade para o desenvolvimento de sites mais acessíveis, incluindo, aspectos que podem gerar grandes benefícios a pessoas com problemas de linguagem, deficiência cognitiva e de memória, tais como, a distribuição de conteúdos em pequenos parágrafos; a manutenção do histórico das ações que foram realizadas (onde estou, para onde vou e de onde vim); a simplicidade e a organização das telas.

\subsection{User Experience}

Ciente das recomendações da Acessibilidade Web Cognitiva, buscou-se a apropriação do conhecimento sobre a abordagem da User Experience (UX). A UX dispõe de um arcabouço para desenvolver softwares orientados às necessidades dos usuários. Os projetos concebidos com esta abordagem consideram as múltiplas dimensões da percepção humana, incluindo aspectos relacionados ao design (e.g. hardware, software, interface, usabilidade, facilidade de busca), aspectos afetivos e experienciais, significativos e valiosos de interação humano-computador (Norman, 2017).

Morville (2005) utilizou o diagrama de três círculos (lado esquerdo da Figura 1) como ferramenta para explicar como e por que encontrar um equilíbrio único em cada projeto. Entre 
eles estão os objetivos e contexto, as necessidades do usuário, o comportamento e o conteúdo. A boa experiência consiste em identificar o usuário, seu comportamento e suas necessidades para assim poder organizar e disponibilizar os conteúdos. O contexto é a parte fundamental para estruturar a experiência do usuário e leva-se em consideração a situação, o ambiente e a ocasião em que o usuário interage com determinado conteúdo.

Considerando que a interface é o ponto de contato do usuário com o software, é primordial que o projeto seja orientado a UX Design. A UX Design trata de vários fatores para a boa experiência, sendo alguns desses fatores propostos por Morville (2004) em seu diagrama colmeia (lado direito da Figura 1). O diagrama da colmeia contempla múltiplas dimensões de fatores que podem propiciar uma boa experiência para os usuários.
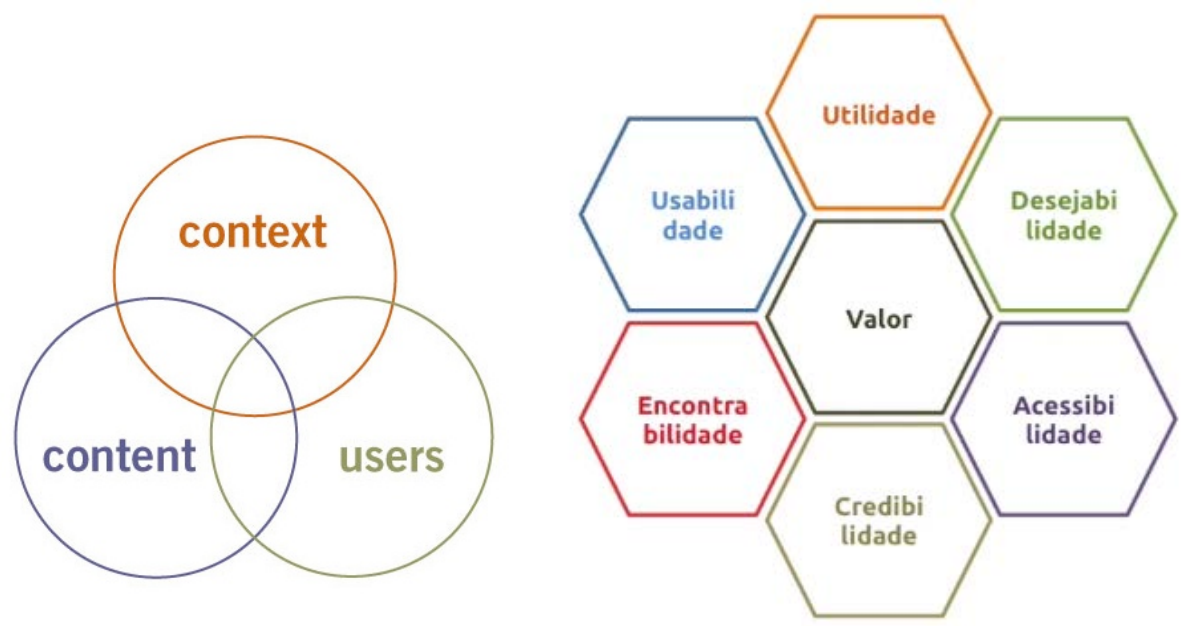

Figura 1: Três círculos da Arquitetura de Informação e Colmeia da UX Design Fonte: Morville, 2005.

Utilidade: o software precisa ser útil e atender as necessidades dos usuários; do contrário não há um propósito real para o mesmo.

Usabilidade: o software deve possibilitar que o usuário realize os objetivos com eficácia, eficiência e satisfação em um contexto específico de uso.

Encontrabilidade: a busca das informações deve ser garantida e de fácil localização. Se no processo de busca o usuário encontrar um problema, o sistema rapidamente deve trazer uma solução. A encontrabilidade também está relacionada com a boa estruturada na navegação e fácil interação.

Credibilidade: o software deve prover informações para passar credibilidade e confiança, com informações de contato.

Acessibilidade: o software deve prover a interação e atender as necessidades dos usuários, sendo adaptado com foco na Acessibilidade Web Cognitiva para remover barreiras de interação.

Desejabilidade: os conteúdos, recursos midiáticos e disponibilização das informações devem ser projetados ao público alvo levando em consideração aspectos de atratividade, simplicidade e objetividade, garantindo que os usuários tenham prazer em usar o software e realizar as atividades.

UX Design contempla vários aspectos que podem prover uma "boa” ou "péssima" experiência do usuário, como por exemplo, desde o tamanho e cor da fonte até os sons reproduzidos na interação do usuário com o sistema. Teixeira (2014) apresenta as disciplinas à 
serem consideradas no UX Design e os artefatos entregáveis ao usuário final. Para o escopo desta pesquisa são abordados a persona, a jornada do usuário, a arquitetura da informação e o wireframe. Tais aspectos se justificam, pelo fato de permitirem a compreensão e a projeção das necessidades e motivações dos usuários.

\subsubsection{Persona}

Persona ou avatar é a representação de supostos tipos de usuários que podem fazer uso do jogo. Para a definição das personas, trabalha-se com personagens fictícios, baseados em pessoas reais. Neste caso, fez-se necessário mapear, entender, segmentar e contemplar diferentes tipos de usuários. Para Melo e Abelheira (2015, p. 67), [...] "persona é uma ferramenta de Empatia, que ajuda a compreender melhor o usuário por meio da criação de seres fictícios. [...] Significa 'máscara', ou 'face' que um indivíduo utiliza para interagir com seu entorno. O objetivo da ferramenta é projetar para um usuário típico que pertence a um grupo, uma comunidade ou organização”.

\subsubsection{Jornada do Usuário}

A jornada descreve o caminho que o usuário realiza para alcançar os principais objetivos do jogo. Ao percorrer um caminho a persona realiza diferentes contatos com o jogo definindo, assim, a interatividade com o ambiente. A jornada do usuário é utilizada para aprofundar o conhecimento e "esmiuçar" os diversos fatores da interação e experiência do uuário com o jogo. Segundo Stickdorn e Schneider (2014, p. 158), “o mapa de jornada do usuário oferece uma visualização vívida, porém estruturada, da experiência do usuário de um serviço. Os pontos de contato por meio dos quais o usuário interage com o serviço são muitas vezes usados para construir uma 'jornada' - uma narrativa envolvente baseada na experiência dos usuários. Essa narrativa detalha suas interações com o serviço e as emoções que acompanham essas interações do modo altamente acessível”.

\subsubsection{Arquitetura da Informação}

A arquitetura é utilizada para gerenciar as informações, facilitar o uso, organizar e categorizar o conteúdo de forma que o usuário consiga atingir seus objetivos com facilidade. A mesma é composta por três grandes sistemas: sistema de organização, que gerencia a organização do conteúdo; sistema de rotulação, que se preocupa com a nomeação do conteúdo; sistema de navegação, que provê forma para que o usuário possa encontrar o conteúdo desejado (Nielsen \& Loranger, 2007).

\subsubsection{Wireframe}

É um desenho básico de uma interface que representa a estrutra da página, delimitando onde ficará cada elemento que o compõe (Teixeira, 2014). O foco é somente o essencial do projeto, de forma simples, sem muitos detalhes, não se atendo à questão estética, mas à arquitetura de informação. O Wireframe será usado posteriormente pelo designer como guia para desenvolvimento do layout final do website, sistema ou aplicativo.

\section{Metodologia da Pesquisa}

Para a reformulação da interface do jogo, a metodologia da pesquisa consistiu de cinco etapas. Inicialmente foi realizada a análise do jogo, evidenciando os aspectos de UX e acessibilidade para atender as necessidades das crianças com autismo. A próxima etapa consistiu na coleta de dados, sendo distribuído um questionário para as mães de crianças com TEA atendidas no Centro Especializado em Reabilitação (CER) na Universidade do Planalto Catarinense 
(UNIPLAC), que concordaram em participar da pesquisa. Para escalar a pesquisa, o mesmo questionário foi disponibilizado em um grupo de mães de crianças com TEA na rede social facebook.

Através da coleta de dados, realizada a partir das respostas do questionário, foi possível conhecer as características das crianças e anseios das mães para definir as personas. Na sequência foi realizado o projeto, seguido do desenvolvimento da nova interface do jogo. E por fim, usando a pesquisa experimental foram realizados os testes de usabilidade com crianças com TEA, para avaliar a interface do jogo, antes e após a reformulação da mesma. A pesquisa foi aprovada pelo Comitê de Ética e Pesquisa (CEP) da UNIPLAC, com o seguinte número de CAAE: 79727817.1.0000.5368.

\subsection{Análise do Ludo Educativo primeiros passos}

O jogo Ludo Educativo Primeiros Passos tem por objetivo auxiliar na alfabetização de crianças. O Ludo Educativo nasceu de uma iniciativa da Aptor Games e Centro de Desenvolvimento de Materiais Funcionais (CDMF), um dos 11 centros de excelência (CEPIDs - Centros de Pesquisa, Inovação e Difusão) da Fundação de Amparo à Pesquisa do Estado de São Paulo (FAPESP) e o Instituto Nacional de Ciência e Tecnologia dos Materiais em Nanotecnologia (INCTMN). Considerando que o jogo foi elaborado para crianças que não apresentam transtorno do neurodesenvolvimento, nesta pesquisa, o mesmo foi analisado para verificar a viabilidade de uso na alfabetização de crianças com TEA.

Para a análise do Ludo foi elaborado um checklist com base na colmeia de UX (Morville, 2004), apresentado na Tabela 1. Os indicadores de cada dimensão foram elaborados seguindo as diretrizes e recomendações de Acessibilidade Web Cognitiva. Cada indicador foi analisado quanto a sua completude, sendo atende completamente (AC), atende parcialmente (AP) e não atende (NA). A análise foi realizada por uma das pesquisadoras deste artigo, especialista na alfabetização de crianças com TEA.

Após a análise e verificação constatou-se que o jogo precisa ser adaptado para ser utilizado por crianças com TEA, pois apresenta aspectos que necessitam de aprimoramento para este público, conforme avaliação exibida na última coluna da Tabela 1. Algumas destas análises são descritas a seguir.

Tabela 1: Checklist para análise da interface do Ludo Educativo

\begin{tabular}{|c|c|c|c|c|c|c|c|}
\hline \multirow[t]{2}{*}{ Dimensões } & \multirow[t]{2}{*}{ Indicadores } & \multicolumn{3}{|c|}{$\begin{array}{c}\text { Análise da } \\
\text { interface } \\
\text { Ludo - versão } \\
\text { original } \\
\end{array}$} & \multicolumn{3}{|c|}{$\begin{array}{c}\text { Análise da } \\
\text { interface do } \\
\text { Ludo - Versão } \\
\text { reformulada }\end{array}$} \\
\hline & & AC & AP & NA & AC & $\mathbf{A P}$ & NA \\
\hline \multirow{3}{*}{ Utilidade } & 1. As instruções são apresentadas de forma clara? & & $\mathrm{x}$ & & $\mathrm{x}$ & & \\
\hline & $\begin{array}{l}\text { 2. Contém palavras de fácil entendimento para } \\
\text { quem está iniciando a fase de alfabetização? }\end{array}$ & & & $\mathrm{X}$ & $\mathrm{x}$ & & \\
\hline & 3. As imagens fazem parte do cotidiano/interesse? & & & $\mathrm{x}$ & $\mathrm{X}$ & & \\
\hline \multirow{5}{*}{ Usabilidade } & 4. Apresenta erros/dicas como feedback? & & & $\mathrm{x}$ & $\mathrm{x}$ & & \\
\hline & 5. Contém comandos autoexplicativos? & & & $\mathrm{x}$ & $\mathrm{x}$ & & \\
\hline & 6. O padrão de textos e botões são condizentes? & & $\mathrm{x}$ & & $\mathrm{x}$ & & \\
\hline & $\begin{array}{l}\text { 7. Permite inclusão de elementos presentes na rotina } \\
\text { da criança? }\end{array}$ & & & $\mathrm{x}$ & $\mathrm{X}$ & & \\
\hline & $\begin{array}{l}\text { 8. Qualidade de elementos secundários e animações } \\
\text { estão moderados de forma que não prejudique o } \\
\text { desenvolvimento das atividades propostas? }\end{array}$ & & & $\mathrm{x}$ & $\mathrm{x}$ & & \\
\hline
\end{tabular}




\begin{tabular}{|c|c|c|c|c|c|c|c|}
\hline \multirow[t]{2}{*}{ Dimensões } & \multirow[t]{2}{*}{ Indicadores } & \multicolumn{3}{|c|}{$\begin{array}{c}\text { Análise da } \\
\text { interface } \\
\text { Ludo - versão } \\
\text { original } \\
\end{array}$} & \multicolumn{3}{|c|}{$\begin{array}{c}\text { Análise da } \\
\text { interface do } \\
\text { Ludo - Versão } \\
\text { reformulada }\end{array}$} \\
\hline & & AC & AP & NA & AC & $\mathbf{A P}$ & NA \\
\hline & 9. A interface é simples e com poucos elementos? & & & $\mathrm{x}$ & $\mathrm{x}$ & & \\
\hline & $\begin{array}{l}\text { 10. Existe coerência no tamanho e existência de } \\
\text { espaçamentos deixados em branco entre } \\
\text { elementos? }\end{array}$ & & $\mathrm{x}$ & & $\mathrm{x}$ & & \\
\hline & $\begin{array}{l}\text { 11. As instruções apresentadas estão em diferentes } \\
\text { formatos, como textos, imagens e áudio? }\end{array}$ & & $\mathrm{x}$ & & & $\mathrm{X}$ & \\
\hline & $\begin{array}{l}\text { 12. Botões e controles seguem o mesmo padrão e } \\
\text { com comportamentos previsíveis? }\end{array}$ & & & $\mathrm{x}$ & $\mathrm{x}$ & & \\
\hline Encontrabilidade & 13.Existe um indicador de localização? & & & $\mathrm{X}$ & $\mathrm{X}$ & & \\
\hline \multirow{3}{*}{ Credibilidade } & $\begin{array}{l}\text { 14. Contém campos para entrar em contato ou } \\
\text { apoiadores do projeto? }\end{array}$ & $\mathrm{x}$ & & & & $\mathrm{X}$ & \\
\hline & $\begin{array}{l}\text { 15. O design é profissional e adaptado para sua } \\
\text { finalidade? }\end{array}$ & & & $\mathrm{x}$ & $\mathrm{x}$ & & \\
\hline & $\begin{array}{l}\text { 16. Apresenta uso de tecnologias atuais, confiáveis e } \\
\text { com bom funcionamento? }\end{array}$ & & & $\mathrm{x}$ & $\mathrm{x}$ & & \\
\hline \multirow{10}{*}{ Acessibilidade } & $\begin{array}{l}\text { 17. Permite ocultar anúncios e deixar a interface em } \\
\text { tela cheia? }\end{array}$ & & & $\mathrm{x}$ & $\mathrm{x}$ & & \\
\hline & $\begin{array}{l}\text { 18. Permite que o usuário personalize a interface } \\
\text { como desejar (através de cores, tamanhos de } \\
\text { fontes e auto contraste)? }\end{array}$ & & & $\mathrm{x}$ & & $\mathrm{x}$ & \\
\hline & 19. Apresenta sons adequados a criança com TEA? & & & $\mathrm{x}$ & & $\mathrm{x}$ & \\
\hline & $\begin{array}{l}\text { 20. Os parágrafos possuem tamanhos adequados a } \\
\text { criança com TEA? }\end{array}$ & & & $\mathrm{x}$ & $\mathrm{x}$ & & \\
\hline & $\begin{array}{l}\text { 21. Contém formas de fornecer áudio para que } \\
\text { palavras sejam lidas em voz alta e opção para } \\
\text { retirar o áudio? }\end{array}$ & & $\mathrm{x}$ & & & & $\mathrm{X}$ \\
\hline & 22.Imagens podem ser ampliadas? & & & $\mathrm{x}$ & & & $\mathrm{x}$ \\
\hline & 23.A área de clique dos botões é eficiente? & & $\mathrm{x}$ & & $\mathrm{x}$ & & \\
\hline & $\begin{array}{l}\text { 24. Existem formas diferentes de transmitir a } \\
\text { informação (cores)? }\end{array}$ & $\mathrm{x}$ & & & $\mathrm{x}$ & & \\
\hline & 25.Família tipográfica apresentada é adequada? & & $\mathrm{x}$ & & $\mathrm{x}$ & & \\
\hline & 26. Os textos são alinhados? & & $\mathrm{x}$ & & $\mathrm{x}$ & & \\
\hline Desejabilidade & $\begin{array}{l}\text { 27. Contém elementos que despertam o desejo da } \\
\text { criança com TEA? }\end{array}$ & & $\mathrm{x}$ & & $\mathrm{x}$ & & \\
\hline
\end{tabular}

A Figura 2 apresenta a tela que dá acesso ao Ludo. Observa-se que a interface contém anúncios, propagandas, alguns elementos e um número considerável de informações, o que pode ser complexo, não direcionar, induzir ao erro e causar desconforto às crianças com TEA. Nielsen e Loranger (2007, p. 246) esclarecem que "usuários com diferentes tipos de deficiência têm problemas específicos para gerenciar janelas extras. Pessoas com dificuldades de coordenação motora certamente não querem clicar em caixas de fechamento indesejáveis” (telas de anúncios). 


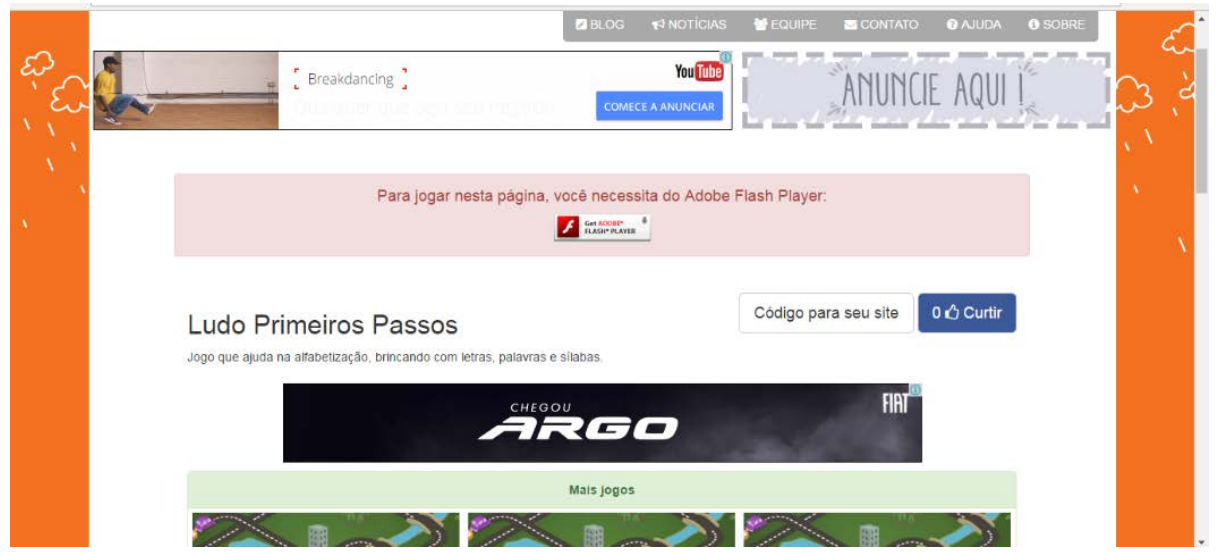

Figura 2 - Tela de Acesso ao Ludo Primeiros Passos Fonte: Print Screen do Ludo Primeiro Passos

A Figura 3 apresenta a tela inicial (lado esquerdo) e a tela de instrução do jogo (lado direito). Em ambos as telas há opacidade reduzida (baixo contraste) exibindo os elementos do fundo, o que pode dificultar "a compreensão, a legibilidade e pode prejudicar a atenção da pessoa com TEA” (Britto, 2016. p. 3).
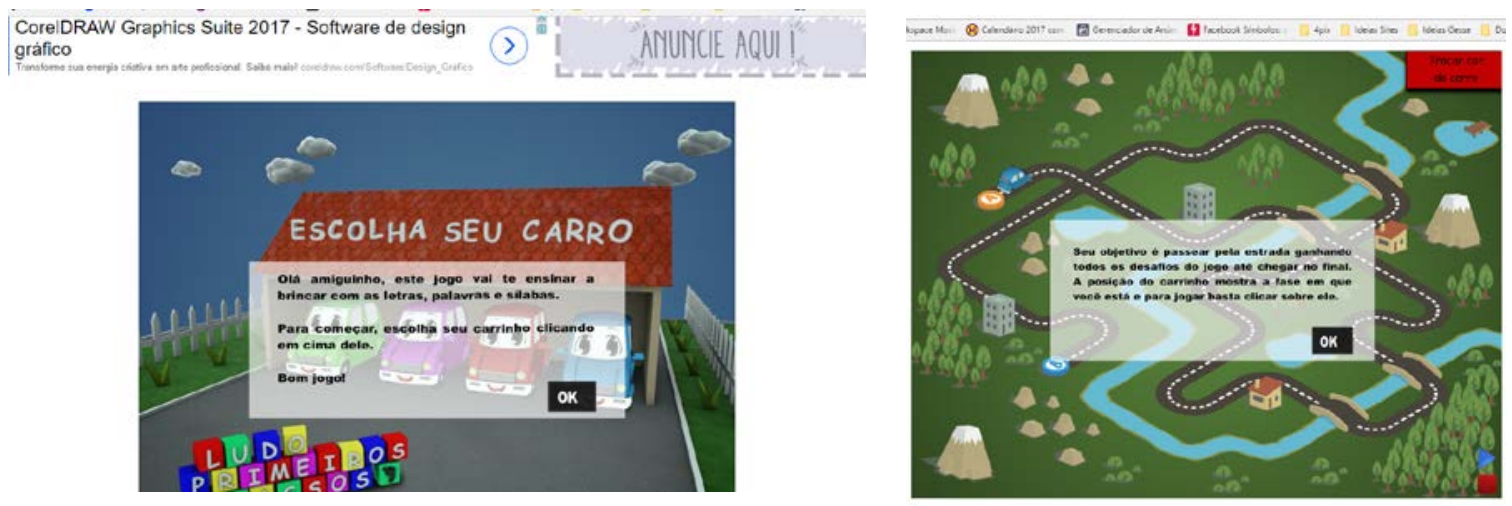

Figura 3 - Tela Inicial e Tela de Instrução do Ludo Primeiros Passos Fonte: Print Screen do Ludo Primeiro Passos

A tela, lado esquerdo da Figura 3, contém a animação com o texto "escolha seu carro", mas a primeira ação que o usuário deve fazer é clicar no botão “OK”, posteriormente pode ser feita a escolha do carro. Além da apresentação de duas tarefas a serem realizadas pela criança na mesma tela, ao selecionar o carro é emitido um som de buzina. As pessoas com TEA tendem a ter mais sensibilidade a determinados sons o que pode gerar desconforto e perturbação (Britto, 2016). Em adição, de acordo com recomendações do Webaim (2014), devem ser evitadas animações, imagens contrastantes ou outras distrações que retirem atenção do conteúdo (anúncio, propaganda, janelas pop-up).

Outro aspecto a considerar consiste na jornada do usuário. No jogo, o próximo passo do usuário é incerto, como mostra a tela de escolha de fase para iniciar o jogo, Figura 4. A seleção do local onde o usuário deve clicar só aparece após passar o cursor sobre o elemento. O Jogo oferece uma instrução de clique, porém de acordo com Nielsen e Loranger (2007, p.97) "sempre que precisa fornecer instruções onde os usuários podem clicar fica claro que você tem um problema de usabilidade”. 


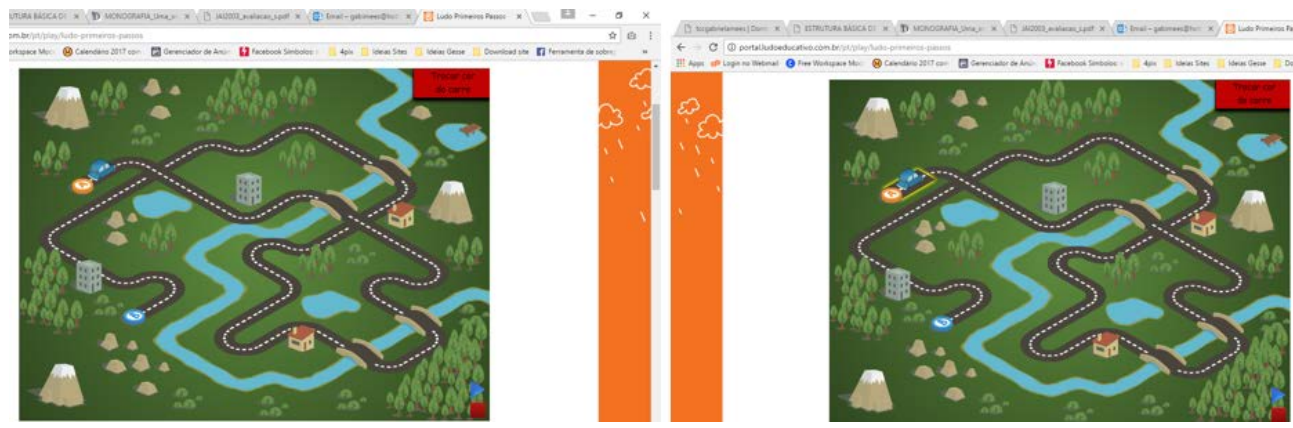

Figura 4 - Tela de escolha de fase para iniciar o jogo Fonte: Print Screen do Ludo Primeiro Passos

$\mathrm{Na}$ análise verificou-se ambiguidade e complexidade no entendimento dos desenhos apresentadas na atividade de completar as letras ausentes na palavra, especialmente para crianças com TEA em fase de alfabetização. Nessa atividade, o jogo contempla desenhos que podem ter mais de um significado, por exemplo, desenho de anjo x cúpido, jegue x burro; desenhos de compreensão complexa; palavras complexas como "hospital, televisão, bexiga" e palavras que nem sempre fazem parte do cotidiano das crianças, como "querosene, xilofone, dromedário" (Figura 5). A W3C (Seeman \& Cooper, 2018a) recomenda evitar o uso de termos e nomes não familiares para os autistas, e a WebAIM (2014) sugere o uso de imagens e ícones, como apoio ao texto, para facilitar a transmissão do conteúdo.

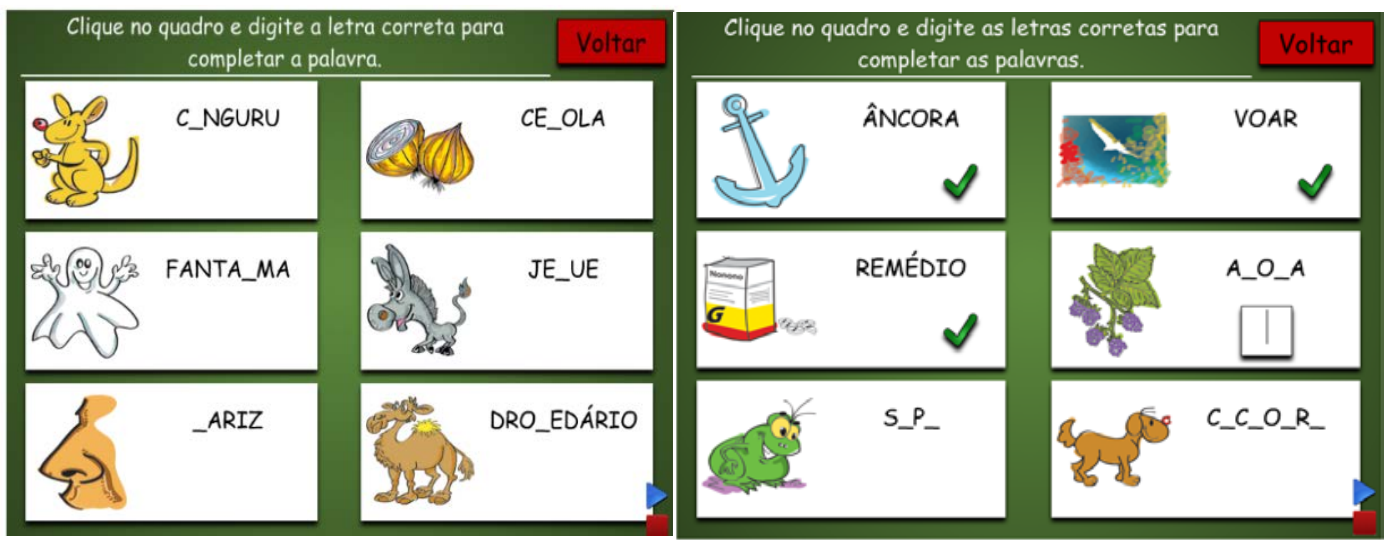

Figura 5 - Tela de atividades para completar a palavra através de digitação Fonte: Print Screen do Ludo Primeiro Passos

Nas telas para clicar e arrastar as figuras que começam com a mesma letra (Figura 6), ao cometer um erro, não há feedback e a interface continua estática como estava anteriormente ao erro (Figura 6, lado esquerdo). Para Britto (2016) os feedbacks são importantes para usuários com TEA, pois auxiliam na realização de tarefas, colaboram para entender o comportamento do software e permitem prever o comportamento de elementos ou funcionalidades semelhantes.

Na mesma atividade, a única forma de mostrar que a imagem foi selecionada é através do realce (Figura 6, lado direito), mas, a mesma não tem muito destaque em relação ao fundo, pode passar despercebida por crianças com TEA. E por último, o botão para avançar à próxima atividade (seta de cor azul na Figura 6) não tem muito destaque em relação ao fundo, retornando ao problema citado anteriormente, sobre a incerteza do clique. Para Britto (2016, p. 3), “o baixo contraste entre o fundo e o texto/objeto de primeiro plano dificulta a compreensão, a legibilidade e pode prejudicar a atenção da pessoa com TEA. Entretanto, as cores dos objetos e os diferentes contrastes podem ser usados para guiar a atenção e diferenciar elementos”. 

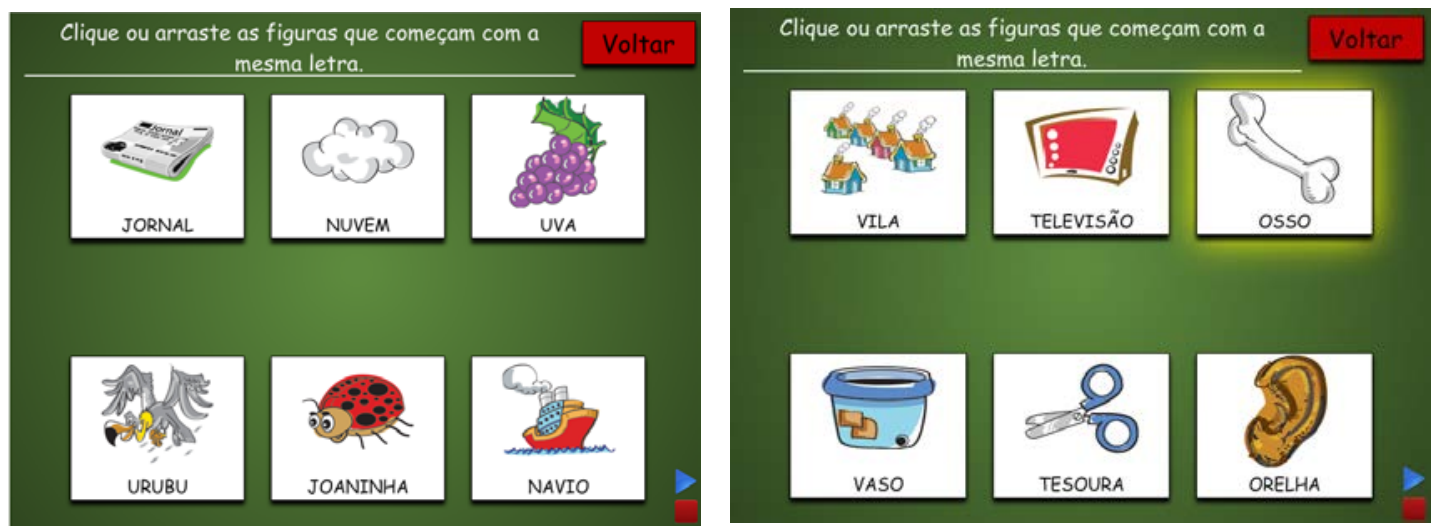

Figura 6 - Tela de atividades para completar a palavra através do clicar e arrastar a figura Fonte: Print Screen do Ludo Primeiro Passos

\subsection{Coleta de dados com as mães das crianças com TEA}

Para conhecer as crianças e os anseios das mães foi utilizado um questionário estruturado de 19 questões. A aplicação do questionário permitiu obter informações da mãe e da criança. Informações da mãe: nome, idade e grau de instrução; desejo em relação a formação humana da criança; qual a maior preocupação como mãe de uma criança com TEA. Informações da criança: nome; idade; local de moradia; se frequenta o ensino regular e/ou APAE (Associação de Pais e Amigos dos Excepcionais), qual série/ano o aluno frequenta; está em fase de alfabetização; apresenta diagnóstico, qual o nível do TEA; cor favorita; personagem favorito; qual o desenho animado/filme favorito; ídolos; dispositivos eletrônicos e/ou digitais utilizados pela criança; qual a relação da criança com a tecnologia; uso da internet para pesquisas/atividades, quais os principais assuntos de interesse da criança; utiliza algum aplicativo/jogo educativo; motivações da criança para a aprendizagem; maiores desafios da criança (comportamentos, informática e alfabetização); quais as principais facilidades/dificuldades da criança.

O questionário foi respondido por trezes mulheres - mães de crianças com TEA, sendo que apenas cinco delas participaram dos experimentos junto com os seus filhos. Entre tantas informações obtidas, destaca-se que todas as crianças que participaram dos experimentos foram diagnosticadas por especialistas, com o respectivo nível de gravidade de TEA, sendo: uma criança com nível 3 e Transtorno Desafiador de Oposição (TOD); uma criança com grau leve ao moderado; duas crianças com Síndrome de Asperger e uma criança com grau 1 (Leve).

Todas as crianças tem familiaridade no uso de tecnologias digitais, embora, com variabilidade no uso, sendo que algumas usam as tecnologias com muita frequência e outras, apenas esporadicamente.
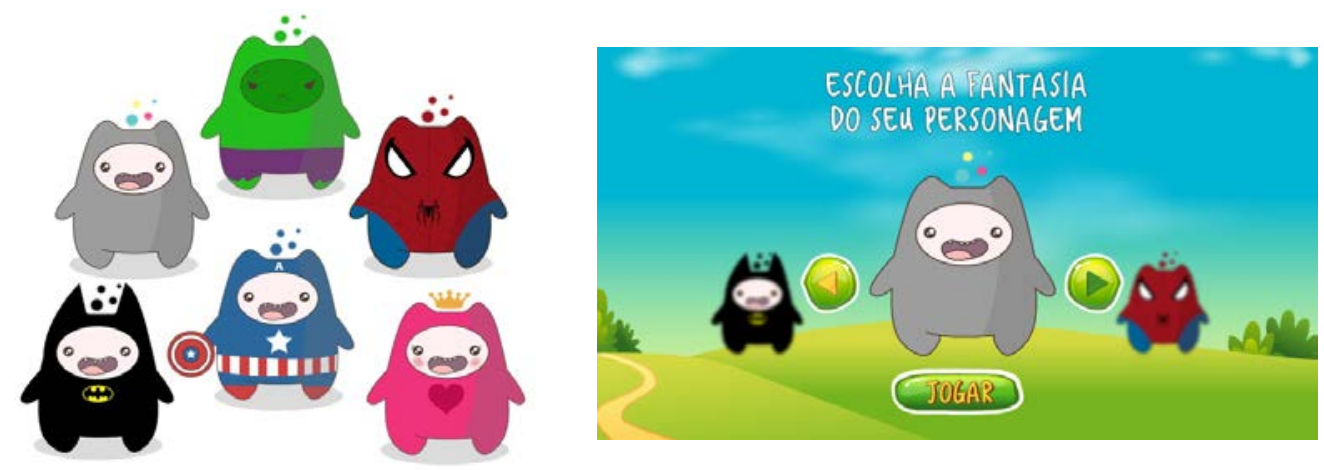

Figura 7 - Personagens do jogo criados conjuntamente com as crianças. 
As informações obtidas foram primordiais para o desenvolvimento do projeto, a criação dos personas e a definição de um personagem para o jogo. Como todas as crianças tinham um herói ou ídolos de desenhos animados, idealizou-se um bonequinho, desprovido de gênero, com a possibilidade de trocar de roupa tornando-se um herói ou uma princesa. Após essa definição, o boneco físico foi para produção (costureira) e o lógico foi inserido na interface inicial do jogo (Figura 7). O boneco físico foi entregue aos participantes (crianças com TEA) no dia dos testes de usabilidade.

\subsection{Projeto da Nova Interface do Jogo Ludo Educativo Primeiros Passos}

Após a análise do Ludo na versão orginal e coleta de dados com as mães iniciou-se o projeto e desenvolvimento da nova interface do jogo. O projeto contemplou os seguintes artefatos: persona; jornada do usuário; arquitetura da informação e wireframe.

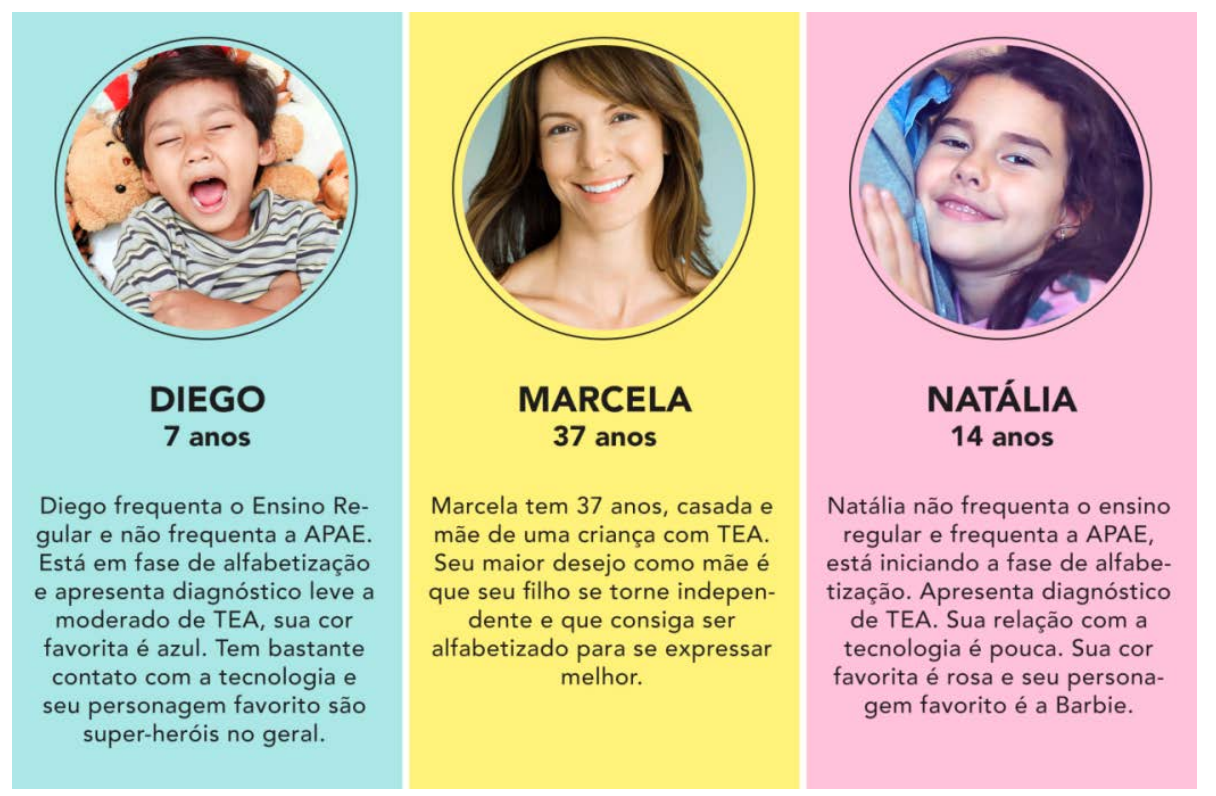

Figura 8 - Definição das Personas.

A Figura 8 apresenta as personas, duas delas representam o usuário principal da aplicação, criança com TEA e a terceira representa a mãe de uma criança com TEA. A mãe é uma stakeholder, pois é a maior conhecedora dos hábitos, costumes, comportamentos e necessidades da criança, logo, ajudou na coleta de insights, objetivos e funcionalidades da interface, mas, ela também é uma usuária do software. Torna-se usuária para motivar a criança usar o jogo e também para auxiliar na proposição de melhorias em novas versões, considerando que a criança é assistida pela mesma.

Com a análise e verificação do ludo na versão original (seção 3.1) e a definição das personas (dados demográficos, comportamentos, necessidades e motivações das crianças com TEA), elaborou-se a jornada do usuário levando-se em consideração as diretrizes de acessibilidade web cognitiva (seção 2.2.) e os aspectos da UX, apresentados na Tabela 1.

A jornada do usuário (Figura 9) é essencial para garantir uma boa experiência da criança com o jogo, pois com ela é possível mapear o caminho, ações, navegabilidade, quantos passos (cliques) para efetivar uma tarefa. Com isso, organizou-se o fluxo de navegação e a utilização do jogo pelas personas em uma perspectiva individual. 


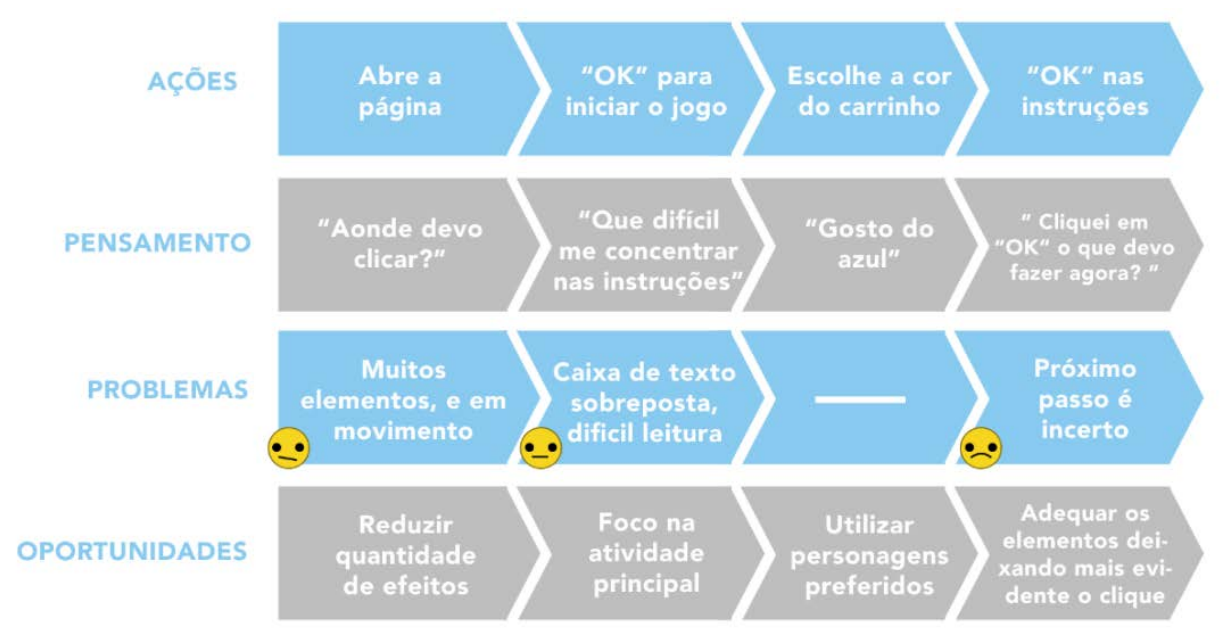

Figura 9 - Jornada do Usuário.

Para prover uma boa experiência da criança na interação com o jogo, foram mapeadas as ações do Ludo na versão original, o esforço cognitivo que a criança com TEA precisa realizar, os problemas aparentes na interface original e as oportunidades de melhorias a serem implementadas na nova interface do jogo.

Na Figura 9, as ações correspondem com a sequência de passos que o Ludo (versão original) possibilita a criança realizar para iniciar o jogo. As ações desencadeiam atividades cognitivas, a criança faz questionamentos, faz escolhas e tem uma experiência. Alguns questionamentos nem sempre são passíveis de respostas e a configuração do ambiente pode levar a criança a caminhos incertos, surgindo os problemas.

Conforme apresentado na seção 3.1, ao abrir a página inicial do jogo, a criança se depara com muitos elementos e em movimentos na tela (propagandas, anúncios, excesso de informações), neste caso, as oportunidades consistem em reduzir a quantidade de efeitos, informações e elementos; prover uma interface limpa para focar na atividade principal; permitir que a criança utilize um personagem preferido (com base em seus gostos, como por exemplo, um herói, ilustrado na Figura 7) e prover navegabilidade com maior grau de certeza e condução.

Para permitir que a criança com TEA consiga navegar no jogo de forma orientada para atingir os seus objetivos, a arquitetura da informação do jogo Ludo Primeiros Passos foi planejada com localização facilitada, deixando o caminho e a jornada da criança mais simples e prática, conforme esquema apresentada na Figura 10.

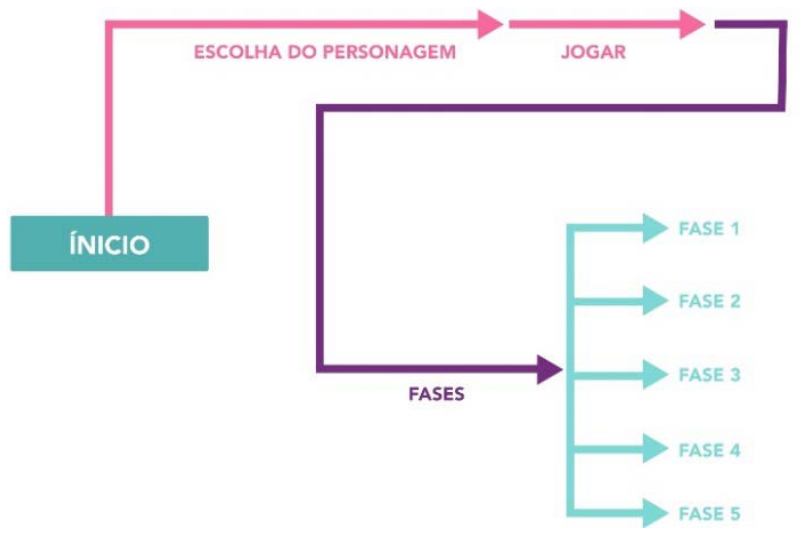

Figura 10 - Nova arquitetura da Informação. 
E por último, construiu-se o desenho da nova interface, Wireframe, (Figura 11), contemplando as ideias iniciais elaboradas e trabalhadas à nova interface do jogo Ludo Educativo.

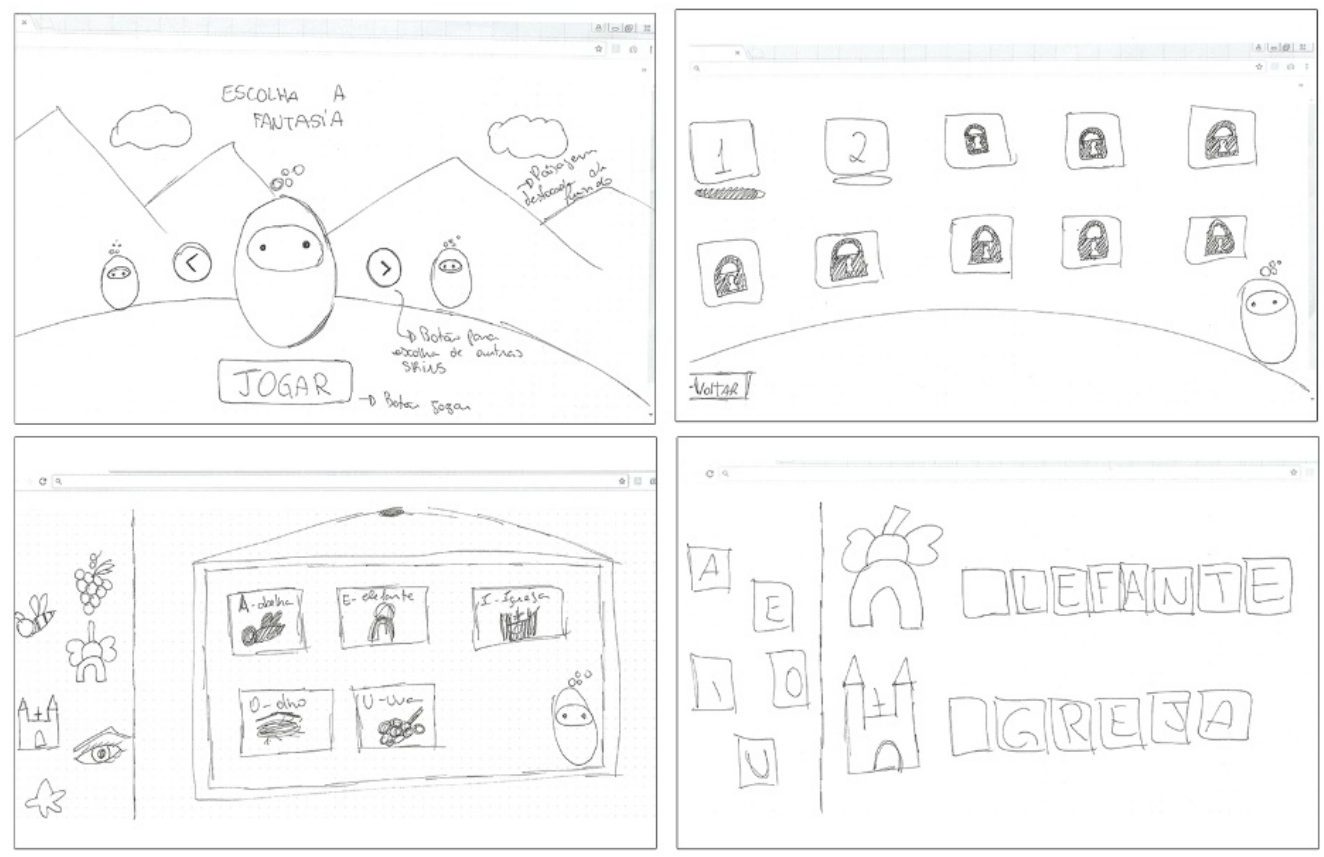

Figura 11 - Wireframe das telas principais da nova interface do Ludo Educativo Primeiros Passos

\subsection{Nova Interface Gráfica do Jogo Ludo Educativo Primeiros Passos}

Nesta seção são apresentadas as principais telas reformuladas, comparando-as com as interfaces originais. Para validar a proposta inicial da interface foram desenvolvidas quatro fases para trabalhar com as vogais.

Para Britto (2016, p. 20) “pessoas com TEA podem ter dificuldade para prestar atenção ao conteúdo primário apresentado na tela devido à distração de conteúdo secundário, portanto, é preciso evitar inserir elementos animados, que piscam ou brilham, bem como sons de fundo, pois eles podem ser incômodos e prejudicar o foco". No entanto, a interface original do Ludo (lado esquerdo da Figura 12) apresenta o objeto "carrinho" sobreposto ao campo de instrução que por sua vez contém a opacidade reduzida, exibindo os elementos do fundo da tela. Além disso, ao selecionar o objeto "carrinho" é emitido um som de buzina, que pode ser perturbador, pois crianças com TEA tendem a ter mais sensibilidade a determinados sons. Observa-se, ainda, que a tela principal possui anúncios que podem induzir a criança ao erro e a perda do foco. Para contornar todos esses problemas, a nova interface da tela principal (lado direito da Figura 12) foi projetada com botões intuitivos e diretos, além de conter o personagem principal (herói contruído com a coparticição das crianças), com a possibilidade de escolha da fantasia. 


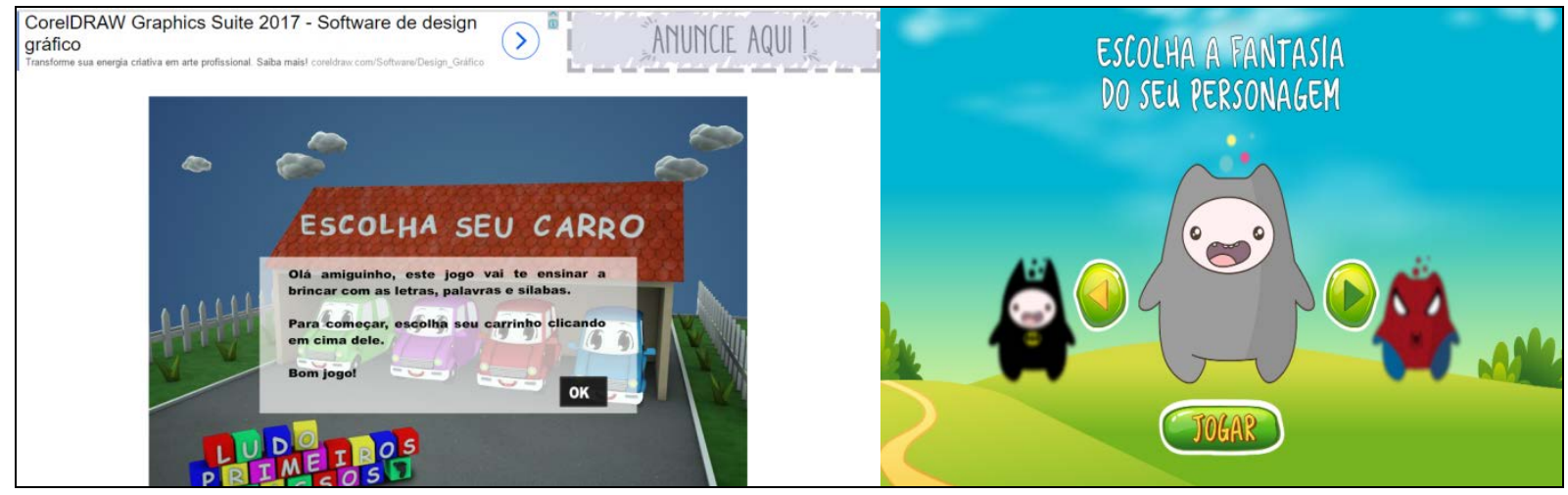

Figura 12 - Tela Inicial (Antes e Após Reformulação da Interface).

Na tela de fases (lado esquerdo da Figura 13) os mesmos problemas se repetem (baixo contraste, elementos de fundo, pouco destaque do botão para avançar a fase). Outro aspecto a ser considerado consiste na incerteza do próximo passo do usuário, pois a seleção do local onde a criança deve clicar só aparece após passar o cursor sobre um determinado objeto. Na nova interface as fases do jogo são apresentadas de forma direta (lado direito da Figura 13). Quando a criança completa a primeira fase, a barra de progresso fica completa e com uma estrela. Após a conclusão da fase, a seguinte é automaticamente liberada, mantendo as outras bloqueadas.

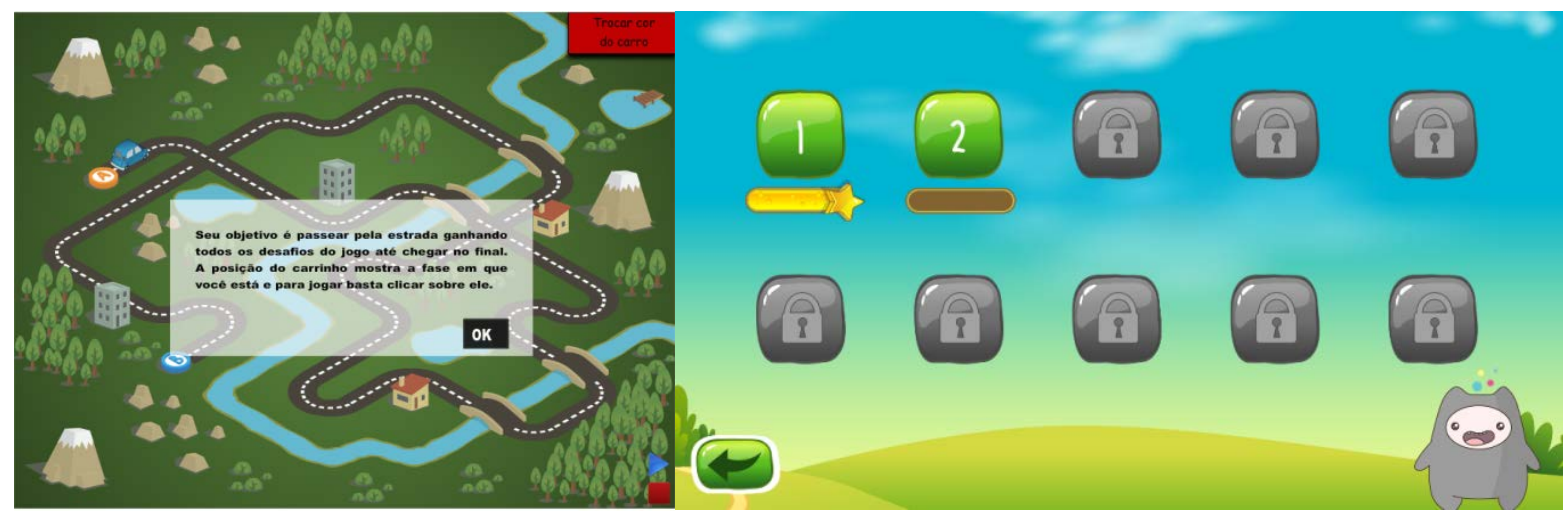

Figura 13 - Tela com as Fases do Jogo (Antes e Após Reformulação).

A análise da interface gráfica, na versão original do Ludo (Figura 14, parte superior), permitiu evidenciar, ainda, que problemas podem ser ocasionados na atividade para completar as letras faltantes nas palavras, seja por ambiguidades nas imagens (imagem do jegue pode ser conhecida pela criança como a imagem de um burro) ou por apresentar palavras complexas ou não usuais (dromedário). Na nova interface (Figura 14, parte inferior), visando melhorar a experiência da criança com o jogo, estes aspectos foram saneados. A parte inferior da Figura 14 apresenta duas das principais fases contidas no protótipo inicial do jogo e o comparativo com as fases da versão original do Ludo Educativo. Essas fases foram usadas no teste de usabilidade junto com as crianças. 


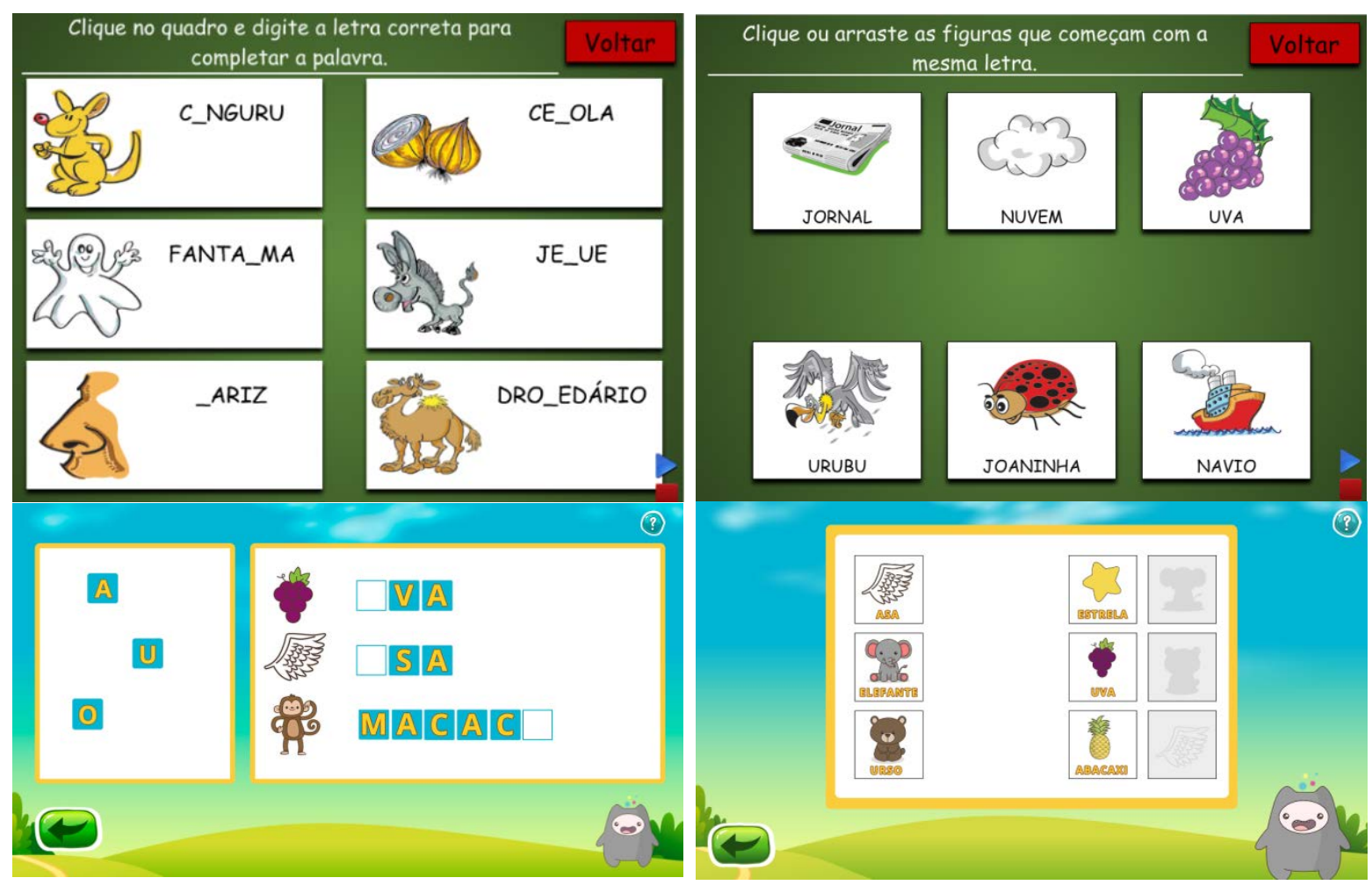

Figura 14 - Telas de Comparativos de Fases (Antes e Após a Reformulação)

Ao clicar na fase liberada, antes de iniciar o jogo, é exibida uma instrução visual para a criança (lado esquerdo da Figura 15). E ao terminar a fase com êxito, é apresentada uma mensagem de parabéns, que traz o botão de "próxima fase” induzindo ao clique e condução para a próxima fase do jogo (lado direito da Figura 15).
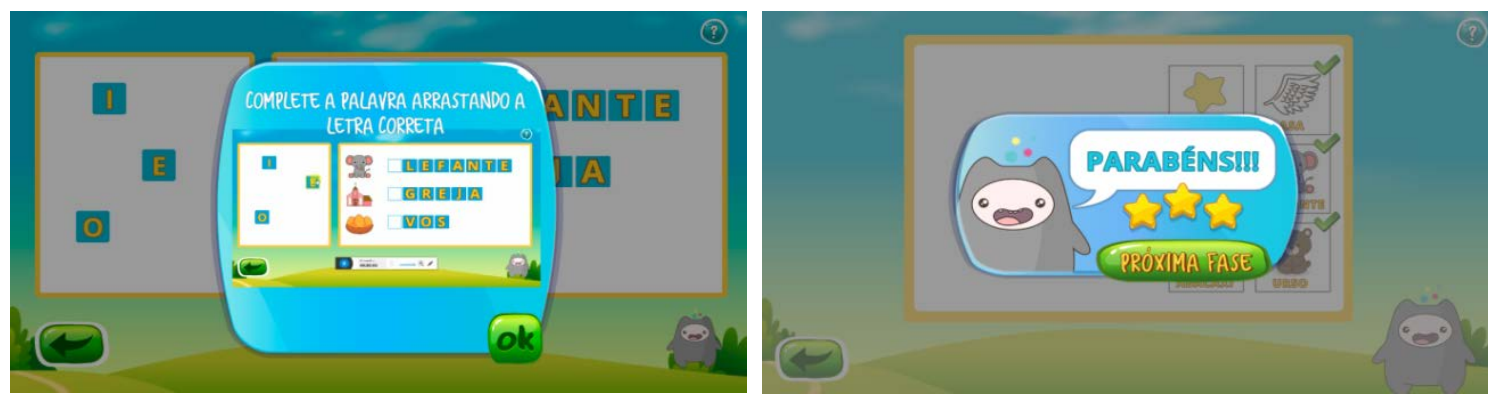

Figura 15 - Tela de Instrução e de Parabéns

A Figura 16 apresenta as fases contidas no protótipo inicial do jogo para a realização do teste de usabilidade. Em todas as telas são apresentados os botões de voltar e de dúvida, este último, localizado na parte superior da tela.

As tarefas das $1^{\mathrm{a}}$ e $2^{\mathrm{a}}$ fases consistem em arrastar as vogais para completar a palavra (Figura 16, parte superior). As tarefas das $3^{\mathrm{a}}$ e $4^{\mathrm{a}}$ fases são apresentadas, respectivamente, na Figura 16 , parte inferior. $\mathrm{Na} 3^{\mathrm{a}}$ fase, a criança deve deixar as imagens que começam com a mesma letra lado a lado. Havendo erro na realização da tarefa é apresentado um estímulo visual para a correção antes de encerrar a fase. Por fim, na $4^{\text {a }}$ fase, a criança tem que arrastar as imagens do primeiro até o segundo quadro, para o nome correspondente. Após a conclusão desta fase é apresentado uma mensagem de "Incrível, você completou todos os níveis. Parabéns!”. 


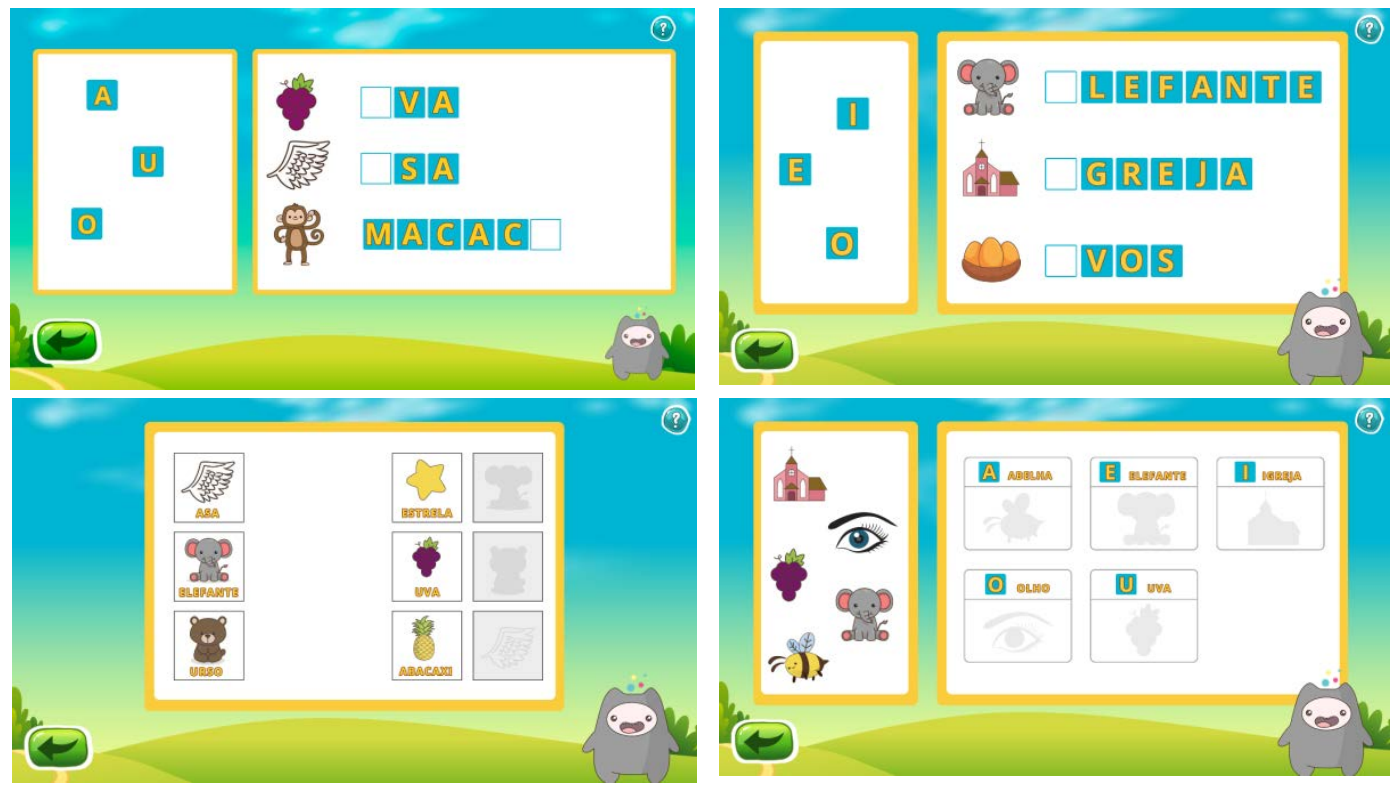

Figura 16 - Respectivas fases do Jogo ( $1^{\mathrm{a}}$. a $4^{\mathrm{a}}$. fases $)$

Após a concretização do projeto uma das autoras desta pesquisa, especialista em alfabetização de autista, fez a avaliação dos aspectos de UX na nova interface, os resultados estão dispostos na última coluna da Tabela 1.

\subsection{Testes de Usabilidade}

Os testes de usabilidade foram realizados em laboratório, com cinco (5) crianças com TEA, atendidas no Centro Especializado em Reabilitação (CER) na UNIPLAC. Cinco mães acompanharam as crianças na realização dos testes.

Os testes foram realizados com a nova e com a interface nativa do jogo. Durante a realização dos testes, foram estimados valores de 12 parâmetros e/ou métricas obtidos a partir da realização das seis (6) tarefas apresentadas na Tabela 2. Inicialmente os testes foram realizados, na nova versão do jogo.

Tabela 2: Atividades e parâmetros do teste de usabilidade.

\begin{tabular}{|l|l|}
\hline Tarefas & Pontos a serem analisados \\
\hline \multirow{2}{*}{ Iniciar o jogo } & 1. Tempo para perceber a ação a ser realizada \\
& 2. Tempo para escolher o personagem principal \\
& 3. Quantidade de cliques para escolher o personagem principal \\
& 4. Tempo médio para ir para a tela de fases \\
\hline \multirow{2}{*}{ Iniciar uma fase do jogo } & $\begin{array}{l}\text { 5. Tempo para clicar na primeira fase } \\
\text { 6. Quantidade de passos para iniciar a primeira fase }\end{array}$ \\
\cline { 1 - 2 } Completar a atividade proposta na $1^{\text {a }}$ fase & 7. Apresentou erros \\
\hline Completar a atividade proposta na $2^{\text {a }}$ fase & 9. Quantidade de passos para completar as atividades propostas \\
\cline { 1 - 1 } Completar a atividade proposta na $3^{\text {a }}$ fase & 10. Taxa de dificuldade para realizar a atividade \\
\cline { 1 - 2 } Completar a atividade proposta na $4^{\text {a }}$ fase & 11. Taxa de satisfação \\
\hline
\end{tabular}

Para o desenvolvimento dos testes das interfaces, cada criança tentou realizar e concluir as tarefas propostas no jogo, enquanto o analista observava, ouvia e anotava. No decorrer dos testes alguns pontos foram observados. No primeiro momento, da escolha dos personagens, três crianças, sendo a maioria, necessitaram de auxílio. Também ocorreram algumas dificuldades em 
relação ao uso da tecnologia. Uma das crianças era adaptada apenas ao touch screen, o que a impossibilitou de realizar as tarefas propostas.

Tabela 3: Resultados do teste de usabilidade para a escolha do personagem.

\begin{tabular}{|c|c|c|c|c|c|c|}
\hline Participante & Nível TEA & $\begin{array}{l}\text { Tempo } \mathrm{p} / \\
\text { perceber a } \\
\text { ação a ser } \\
\text { realizada }\end{array}$ & $\begin{array}{l}\text { Tempo p/ a } \\
\text { escolha do } \\
\text { personagem }\end{array}$ & $\begin{array}{l}\text { Quant. de cliques } \\
\text { p/ realizar a tarefa }\end{array}$ & $\begin{array}{l}\text { Realizaç } \\
\text { ão do } \\
\text { objetivo }\end{array}$ & $\begin{array}{l}\text { Necessitou } \\
\text { ajuda? }\end{array}$ \\
\hline $\begin{array}{c}\text { Criança A } \\
\text { (Menina, } 14 \text { anos) }\end{array}$ & $\begin{array}{c}3+\text { TOD } \\
\text { (Transtorno } \\
\text { desafiador de } \\
\text { oposição) }\end{array}$ & $\begin{array}{c}0: 19 \\
\text { segundos }\end{array}$ & 0:05 segundos & $\begin{array}{l}3 \text { cliques (auxílio) } \\
1 \text { clique criança }\end{array}$ & Sim & Sim \\
\hline $\begin{array}{c}\text { Criança B } \\
\text { (Menino, } 5 \text { anos) }\end{array}$ & $\begin{array}{l}\text { Leve à } \\
\text { moderado }\end{array}$ & \multicolumn{5}{|c|}{$\begin{array}{l}\text { Por problemas técnicos, a criança B não conseguiu realizar as atividades, pois } \\
\text { era adaptada apenas a tela touch screen. }\end{array}$} \\
\hline $\begin{array}{c}\text { Criança C } \\
\text { (Menina, } 9 \text { anos) }\end{array}$ & $\begin{array}{l}\text { Síndrome de } \\
\text { Asperger }\end{array}$ & $\begin{array}{c}0: 04 \\
\text { segundos }\end{array}$ & 0:04 segundos & $\begin{array}{c}1 \text { clique (escolheu } \\
\text { o } 1^{\circ} \text {. personagem } \\
\text { que apareceu) }\end{array}$ & Sim & Não \\
\hline $\begin{array}{c}\text { Criança D } \\
\text { (Menino, } 9 \text { anos) }\end{array}$ & $\begin{array}{l}\text { Síndrome de } \\
\text { Asperger }\end{array}$ & $\begin{array}{c}\text { 0:03 } \\
\text { segundos }\end{array}$ & 0:03 segundos & $\begin{array}{c}1 \text { clique (escolheu } \\
\text { o } 1^{\circ} \text {. personagem } \\
\text { que apareceu) }\end{array}$ & Sim & Não \\
\hline $\begin{array}{c}\text { Criança E } \\
\text { (Menino, } 4 \text { anos) }\end{array}$ & 1 (Leve) & $\begin{array}{c}\text { 0:04 } \\
\text { segundos }\end{array}$ & 0:27 segundos & $\begin{array}{c}12 \text { cliques } \\
\text { (escolheu o } \\
\text { personagem com } \\
\text { a temática do } \\
\text { Homem-Aranha) }\end{array}$ & Sim & Não \\
\hline
\end{tabular}

A “Criança A”, inicialmente não demostrou interesse, necessitando do apoio da mãe para mostrar a quantidade de personagens disponíveis. A “Criança B” não era habituada a utilizar o mouse, acostumada apenas com tablets e smartphones, o que a impossibilitou de avaliar a interface. Porém, ao se deparar com o notebook, na parte da escolha dos personagens, ela sabia o que fazer, já clicava (com os dedos) nas setas para a escolha do personagem e no botão "jogar" para iniciar o jogo. A grande dificuldade foi não ter uma versão da interface responsiva, ou um notebook com touch screen. A “Criança D” não escolheu personagem (usando as setas), mantendo aquele que estava como padrão na interface, indo direto para o botão "Jogar".

Tabela 4: Resultados do teste de usabilidade para iniciar uma fase no jogo.

\begin{tabular}{|c|c|c|c|c|c|c|}
\hline Participante & Nível TEA & $\begin{array}{c}\text { Tempo p/ } \\
\text { perceber a ação } \\
\text { a ser realizada }\end{array}$ & $\begin{array}{c}\text { Tempo p/ a } \\
\text { escolha da } \\
\text { fase }\end{array}$ & $\begin{array}{c}\text { Quant. de } \\
\text { cliques p/ } \\
\text { realizar a tarefa }\end{array}$ & $\begin{array}{c}\text { Realização } \\
\text { do objetivo }\end{array}$ & $\begin{array}{c}\text { Necessi } \\
\text { tou } \\
\text { ajuda }\end{array}$ \\
\hline $\begin{array}{c}\text { Criança A } \\
\text { (Menina, 14 anos) }\end{array}$ & $3+$ TOD & $0: 12 \mathrm{~s}$ & $0: 12 \mathrm{~s}$ & $\begin{array}{c}1 \text { clique } \\
\text { (necessitava } 1)\end{array}$ & Sim & Não \\
\hline $\begin{array}{c}\text { Criança C } \\
\text { (Menina, } 9 \text { anos) }\end{array}$ & $\begin{array}{c}\text { Síndrome } \\
\text { de } \\
\text { Asperger }\end{array}$ & $0: 14 \mathrm{~s}$ & $0: 14 \mathrm{~s}$ & $\begin{array}{c}3 \text { cliques } \\
\text { (necessitava 1) }\end{array}$ & Sim & Sim \\
\hline $\begin{array}{c}\text { Criança D } \\
\text { (Menino, 9 anos) }\end{array}$ & $\begin{array}{c}\text { Síndrome } \\
\text { de } \\
\text { Asperger }\end{array}$ & $0: 01 \mathrm{~s}$ & $0: 02 \mathrm{~s}$ & $\begin{array}{c}1 \text { clique } \\
\text { (necessitava 1) }\end{array}$ & Sim & Não \\
\hline $\begin{array}{c}\text { Criança E } \\
\text { (Menino, } 4 \text { anos) }\end{array}$ & 1 (Leve) & $0: 02 \mathrm{~s}$ & $0: 04 \mathrm{~s}$ & $\begin{array}{c}1 \text { clique } \\
\text { (necessitava 1) }\end{array}$ & Sim & Não \\
\hline
\end{tabular}


Tabela 5: Resultados dos testes de usabilidade para a $1^{\mathrm{a}}$ fase - após fechar a tela de instrução.

\begin{tabular}{|c|c|c|c|c|c|c|}
\hline Participante & $\begin{array}{c}\text { Nível } \\
\text { TEA }\end{array}$ & $\begin{array}{c}\text { Tempo p/ } \\
\text { perceber a ação } \\
\text { a ser realizada }\end{array}$ & $\begin{array}{c}\text { Tempo p/ arrastar } \\
\text { a letra e completar } \\
\text { a palavra }\end{array}$ & $\begin{array}{c}\text { Quant. de } \\
\text { cliques p/ } \\
\text { realizar a tarefa }\end{array}$ & $\begin{array}{c}\text { Realizaç } \\
\text { ão do } \\
\text { objetivo }\end{array}$ & $\begin{array}{c}\text { Necessi } \\
\text { tou } \\
\text { ajuda }\end{array}$ \\
\hline $\begin{array}{c}\text { Criança A } \\
\text { (Menina, 14 anos) }\end{array}$ & $3+$ TOD & $0: 06 \mathrm{~s}$ & $0: 11 \mathrm{~s}$ & $\begin{array}{c}5 \text { cliques } \\
\text { (necessitava 3) }\end{array}$ & $\begin{array}{c}\text { Sim } \\
0: 55 \mathrm{~s}\end{array}$ & Não \\
\hline $\begin{array}{c}\text { Criança C } \\
\text { (Menina, 9 anos) }\end{array}$ & $\begin{array}{c}\text { Síndrome } \\
\text { de } \\
\text { Asperger }\end{array}$ & $0: 07 \mathrm{~s}$ & $0: 08 \mathrm{~s}$ & $\begin{array}{c}7 \text { cliques } \\
\text { (necessitava 3) }\end{array}$ & $\begin{array}{c}\text { Sim } \\
1 \mathrm{~m} \text { e } \\
23 \mathrm{~s}\end{array}$ & Não \\
\hline $\begin{array}{c}\text { Criança D } \\
\text { (Menino, 9 anos) }\end{array}$ & $\begin{array}{c}\text { Síndrome } \\
\text { de } \\
\text { Asperger }\end{array}$ & $0: 01 \mathrm{~s}$ & $0: 03 \mathrm{~s}$ & $\begin{array}{c}5 \text { cliques } \\
\text { (necessitava 3) }\end{array}$ & $\begin{array}{c}\text { Sim } \\
0: 11 \mathrm{~s}\end{array}$ & Não \\
\hline $\begin{array}{c}\text { Criança E } \\
\text { (Menino, 4 anos) }\end{array}$ & 1 (Leve) & $0: 02 \mathrm{~s}$ & $0: 11 \mathrm{~s}$ & $\begin{array}{c}6 \text { cliques } \\
\text { (Necessitava 3) }\end{array}$ & $\begin{array}{c}\text { Sim } \\
1: 00 \mathrm{~m}\end{array}$ & Não \\
\hline
\end{tabular}

A “Criança A" não necessitou de ajuda para realizar as atividades, conhecia as palavras apresentadas, precisou apenas de estímulo, como por exemplo, “Que animal é esse? Isso mesmo, o elefante! Com que letra ele começa?”. Acertou completar a palavra "Igreja”, errou a palavra “ovos”, mas após o erro, fez a correção arrastando a letra "e” para completar a palavra elefante e depois levou a letra "o" para completar a palavra ovos. A "Criança C" demonstrou dificuldade com o mouse em todas as fases, pois ela era canhota e o mouse estava na posição direita, o que só foi percebido quando ela concluiu todas as fases. Mesmo com esta limitação ela realizou a atividade e com um tempo bom. No entanto, se o mouse estivesse posicionado no lado correto, provavelmente teria um melhor aproveitamento.

Tabela 6: Resultados dos testes de usabilidade da $2^{\mathrm{a}}$ fase - após fechar a tela de instrução.

\begin{tabular}{|c|c|c|c|c|c|c|}
\hline Participante & Nível TEA & $\begin{array}{c}\text { Percepção } \\
\text { da ação a ser } \\
\text { realizada }\end{array}$ & $\begin{array}{c}\text { Arrastar a letra } \\
\text { e completar a } \\
\text { palavra }\end{array}$ & $\begin{array}{c}\text { Quant. de } \\
\text { cliques p/ } \\
\text { realizar a tarefa }\end{array}$ & $\begin{array}{c}\text { Realização } \\
\text { do objetivo }\end{array}$ & $\begin{array}{c}\text { Necessi } \\
\text { tou } \\
\text { ajuda }\end{array}$ \\
\hline $\begin{array}{c}\text { Criança A } \\
\text { (Menina, 14 anos) }\end{array}$ & $3+$ TOD & $0: 01 \mathrm{~s}$ & $0: 05 \mathrm{~s}$ & $\begin{array}{c}10 \text { cliques } \\
\text { (necessitava 3) }\end{array}$ & $\begin{array}{c}\text { Sim } \\
1 \mathrm{~m} \text { e 20s }\end{array}$ & Não \\
\hline $\begin{array}{c}\text { Criança C } \\
\text { (Menina, 9 anos) }\end{array}$ & $\begin{array}{c}\text { Síndrome de } \\
\text { Asperger }\end{array}$ & $0: 01 \mathrm{~s}$ & $0: 03 \mathrm{~s}$ & $\begin{array}{c}4 \text { cliques } \\
\text { (necessitava 3) }\end{array}$ & $\begin{array}{c}\text { Sim } \\
0: 24 \mathrm{~s}\end{array}$ & Não \\
\hline $\begin{array}{c}\text { Criança D } \\
\text { (Menino, 9 anos) }\end{array}$ & $\begin{array}{c}\text { Síndrome de } \\
\text { Asperger }\end{array}$ & $0: 01 \mathrm{~s}$ & $0: 01 \mathrm{~s}$ & $\begin{array}{c}3 \text { cliques } \\
\text { (necessitava 3) }\end{array}$ & $\begin{array}{c}\text { Sim } \\
0: 07 \mathrm{~s}\end{array}$ & Não \\
\hline $\begin{array}{c}\text { Criança E } \\
\text { (Menino, 4 anos) }\end{array}$ & 1 (Leve) & $0: 01 \mathrm{~s}$ & $0: 03 \mathrm{~s}$ & $\begin{array}{c}4 \text { cliques } \\
\text { (necessitava 3) }\end{array}$ & $\begin{array}{c}\text { Sim } \\
0: 26 \mathrm{~s}\end{array}$ & Não \\
\hline
\end{tabular}

Tabela 7: Resultados dos testes de usabilidade da $3^{\text {a }}$ fase - após fechar a tela de instrução.

\begin{tabular}{|c|c|c|c|c|c|c|}
\hline Participante & Nível TEA & $\begin{array}{c}\text { Percepção } \\
\text { da ação a ser } \\
\text { realizada }\end{array}$ & $\begin{array}{c}\text { Arrastar } \\
\text { as figuras }\end{array}$ & $\begin{array}{c}\text { Quant. de cliques p/ } \\
\text { realizar a tarefa }\end{array}$ & $\begin{array}{c}\text { Realização do } \\
\text { objetivo }\end{array}$ & $\begin{array}{c}\text { Necessi } \\
\text { tou } \\
\text { ajuda }\end{array}$ \\
\hline $\begin{array}{c}\text { Criança A } \\
\text { (Menina, 14 anos) }\end{array}$ & $3+$ TOD & $0: 07 \mathrm{~s}$ & $0: 05 \mathrm{~s}$ & $\begin{array}{c}3 \text { cliques } \\
\text { (necessitava 3) }\end{array}$ & $\begin{array}{c}\text { Sim } \\
0: 28 \mathrm{~s}\end{array}$ & Não \\
\hline $\begin{array}{c}\text { Criança C } \\
\text { (Menina, 9 anos) }\end{array}$ & $\begin{array}{c}\text { Síndrome de } \\
\text { Asperger }\end{array}$ & $0: 15 \mathrm{~s}$ & $0: 03 \mathrm{~s}$ & $\begin{array}{c}5 \text { cliques } \\
\text { (necessitava 3) }\end{array}$ & $\begin{array}{c}\text { Sim } \\
0: 37 \mathrm{~s}\end{array}$ & Não \\
\hline $\begin{array}{c}\text { Criança D } \\
\text { (Menino, 9 anos) }\end{array}$ & $\begin{array}{c}\text { Síndrome de } \\
\text { Asperger }\end{array}$ & $0: 01 \mathrm{~s}$ & $0: 01 \mathrm{~s}$ & $\begin{array}{c}3 \text { cliques } \\
\text { (necessitava 3) }\end{array}$ & $\begin{array}{c}\text { Sim } \\
0: 06 \mathrm{~s}\end{array}$ & Não \\
\hline $\begin{array}{c}\text { Criança E } \\
\text { (Menino, 4 anos) }\end{array}$ & 1 (Leve) & $0: 01 \mathrm{~s}$ & $0: 03 \mathrm{~s}$ & $\begin{array}{c}\text { Sim } \\
0: 16 \mathrm{~s}\end{array}$ & Não \\
\hline
\end{tabular}


Tabela 8: Resultados dos testes de usabilidade da $4^{\mathrm{a}}$ fase - após fechar a tela de instrução.

\begin{tabular}{|c|c|c|c|c|c|c|}
\hline Participante & Nível TEA & $\begin{array}{c}\text { Percepção da ação } \\
\text { a ser realizada }\end{array}$ & $\begin{array}{c}\text { Arrastar } \\
\text { as figuras }\end{array}$ & $\begin{array}{c}\text { Quant. de cliques } \\
\text { p/ realizar a tarefa }\end{array}$ & $\begin{array}{c}\text { Realização } \\
\text { do objetivo }\end{array}$ & $\begin{array}{c}\text { Necessitou } \\
\text { ajuda }\end{array}$ \\
\hline $\begin{array}{c}\text { Criança A } \\
\text { (Menina, 14 anos) }\end{array}$ & 3 + TOD & $0: 04 \mathrm{~s}$ & $0: 02 \mathrm{~s}$ & $\begin{array}{c}6 \text { cliques } \\
\text { (necessitava 5) }\end{array}$ & $\begin{array}{c}\text { Sim } \\
0: 36 \mathrm{~s}\end{array}$ & Não \\
\hline $\begin{array}{c}\text { Criança C } \\
\text { (Menina, 9 anos) }\end{array}$ & $\begin{array}{c}\text { Síndrome } \\
\text { de } \\
\text { Asperger }\end{array}$ & $0: 07 \mathrm{~s}$ & $0: 03 \mathrm{~s}$ & $\begin{array}{c}6 \text { cliques } \\
\text { (necessitava 5) }\end{array}$ & $\begin{array}{c}\text { Sim } \\
0: 39 \mathrm{~s}\end{array}$ & Não \\
\hline $\begin{array}{c}\text { Criança D } \\
\text { (Menino, 9 anos) }\end{array}$ & $\begin{array}{c}\text { Síndrome } \\
\text { de } \\
\text { Asperger }\end{array}$ & $0: 02 \mathrm{~s}$ & $0: 01 \mathrm{~s}$ & $\begin{array}{c}5 \text { cliques } \\
\text { (necessitava de 5 } \\
\text { cliques) }\end{array}$ & $\begin{array}{c}\text { Sim } \\
0: 13 \mathrm{~s}\end{array}$ & Não \\
\hline $\begin{array}{c}\text { Criança E } \\
\text { (Menino, 4 anos) }\end{array}$ & 1 (Leve) & $0: 02 \mathrm{~s}$ & $0: 05 \mathrm{~s}$ & $\begin{array}{c}5 \text { cliques } \\
\text { (necessitava 5) }\end{array}$ & $\begin{array}{c}\text { Sim } \\
0: 35 \mathrm{~s}\end{array}$ & Não \\
\hline
\end{tabular}

Conforme observado nas Tabelas 3 a 8, as crianças conseguiram realizar as atividades propostas em todas as fases na nova versão do jogo ( $1^{\mathrm{a}}$ a $4^{\mathrm{a}}$ fases), fato que não aconteceu na versão original do Ludo. Considerando que a versão original não apresentou uma boa experiência do usuário, as crianças tiveram dificuldades de entendimento no seu uso, impossibilitando a realização completa dos testes. A maioria das crianças não conseguiu realizar a tarefa proposta já na $1^{\text {a }}$ fase. Apesar das dificuldades, alguns pontos foram observados o que permitiu gerar um pequeno comparativo com a interface nativa do jogo e a interface proposta (Tabelas 9 a 11).

Tabela 9: Comparativo das interfaces para a escolha do personagem.

\begin{tabular}{|c|c|c|c|}
\hline Interface & Criança & $\begin{array}{l}\text { Percepção da ação a ser } \\
\text { realizada }\end{array}$ & Escolha do Personagem \\
\hline Proposta Nova & \multirow[b]{2}{*}{ Criança A } & $0: 05 s$ & $0: 19 s$ \\
\hline $\begin{array}{l}\text { Ludo Educativo - } \\
\text { Primeiros Passos }\end{array}$ & & $0: 05 s$ & $0: 26 s$ \\
\hline Proposta Nova & \multirow[b]{2}{*}{ Criança C } & $0: 04 \mathrm{~s}$ & $0: 04 s$ \\
\hline $\begin{array}{l}\text { Ludo Educativo - } \\
\text { Primeiros Passos }\end{array}$ & & $0: 05 s$ & $0: 07 s$ \\
\hline Proposta Nova & \multirow{2}{*}{ Criança D } & 0:03s & $\begin{array}{c}\text { 0:03s (escolheu o primeiro personagem } \\
\text { que apareceu) } \\
\end{array}$ \\
\hline $\begin{array}{l}\text { Ludo Educativo - } \\
\text { Primeiros Passos }\end{array}$ & & 0:03s & $\begin{array}{l}\text { 0:06s (escolheu uma das cores do } \\
\text { carrinho) }\end{array}$ \\
\hline Proposta Nova & \multirow[b]{2}{*}{ Criança E } & $0: 27 \mathrm{~s}$ & $0: 04 \mathrm{~s}$ \\
\hline $\begin{array}{l}\text { Ludo Educativo - } \\
\text { Primeiros Passos }\end{array}$ & & \multicolumn{2}{|c|}{ Não conseguiu realizar a atividade na versão original do Ludo } \\
\hline
\end{tabular}

Tabela 10: Comparativo das interfaces para iniciar uma fase no jogo.

\begin{tabular}{|c|c|c|}
\hline Interface & Criança & Iniciar a fase \\
\hline Proposta Nova & \multirow{2}{*}{ Criança A } & $0: 12 \mathrm{~s}$ \\
\cline { 1 - 1 } $\begin{array}{c}\text { Ludo Educativo }- \\
\text { Primeiros Passos }\end{array}$ & \multirow{2}{*}{ Criança C } & $0: 35 \mathrm{~s}$ \\
\cline { 1 - 1 } Proposta Nova & \multirow{2}{*}{ Criança D } & $0: 15 \mathrm{~s}$ (10 cliques/necessitava de 2 cliques $)$ \\
\cline { 1 - 1 } $\begin{array}{c}\text { Ludo Educativo - } \\
\text { Primeiros Passos }\end{array}$ & \multirow{2}{*}{ Criança E } & $0: 02 \mathrm{~s}$ \\
\hline Proposta Nova & Não conseguiu realizar a atividade na versão original do Ludo \\
\hline $\begin{array}{c}\text { Ludo Educativo - } \\
\text { Primeiros Passos }\end{array}$ & & $0: 05 \mathrm{~s}$ \\
\hline Proposta Nova & & $0: 04 \mathrm{~s}$ \\
\hline $\begin{array}{c}\text { Ludo Educativo - } \\
\text { Primeiros Passos }\end{array}$ & &
\end{tabular}


Tabela 11: Comparativo das interfaces na $1^{\mathrm{a}}$ fase.

\begin{tabular}{|c|c|c|c|}
\hline Interface & Criança & $\begin{array}{l}\text { Tempo para } 1^{\circ} \text { clique / } \\
\text { perceber a ação a ser } \\
\text { realizada }\end{array}$ & Realização do Objetivo \\
\hline Proposta Nova & & $0: 06 \mathrm{~s}$ & Sim \\
\hline $\begin{array}{c}\text { Ludo Educativo - } \\
\text { Primeiros Passos }\end{array}$ & Criança A & $\begin{array}{c}\text { Não interagiu com a } \\
\text { interface }\end{array}$ & $\begin{array}{c}\text { Desistiu da atividade, levantou da } \\
\text { cadeira e saiu, mesmo com o estímulo } \\
\text { da mãe }\end{array}$ \\
\hline Proposta Nova & & $0: 07 s$ & Sim \\
\hline $\begin{array}{l}\text { Ludo Educativo - } \\
\text { Primeiros Passos }\end{array}$ & Criança C & $1 \mathrm{~m}$ e $06 \mathrm{~s}$ & Saiu do jogo \\
\hline Proposta Nova & & $0: 01 \mathrm{~s}$ & Sim \\
\hline $\begin{array}{c}\text { Ludo Educativo - } \\
\text { Primeiros Passos }\end{array}$ & Criança D & $\begin{array}{l}\text { 0:17s, clicou em outros } \\
\text { botões disponíveis na tela, } \\
\text { que não relacionados com a } \\
\text { ação a ser realizada, } \\
\text { necessitando de ajuda para } \\
\text { mostrar o funcionamento. }\end{array}$ & Sim \\
\hline Proposta Nova & & $0: 02 \mathrm{~s}$ & Sim \\
\hline $\begin{array}{l}\text { Ludo Educativo - } \\
\text { Primeiros Passos }\end{array}$ & Criança E & \multicolumn{2}{|c|}{ Não conseguiu realizar a atividade na versão original do Ludo } \\
\hline
\end{tabular}

\section{Conclusão}

Neste artigo foi apresentada a reformulação da interface do jogo "Ludo Educativo Primeiros Passos” para auxiliar a alfabetização de crianças com TEA. A reformulação teve como base as recomendações de Acessibilidade Web Cognitiva propostas pela W3C (Seeman \& Cooper, 2018a, 2018b), WebAIM (2014), Projeto Gaia (Pagani Britto \& Pizzolato, 2018; Britto, 2016) e Dias (2003), sendo o projeto orientado a UX (Morville, 2005).

Um checklist foi elaborado para avaliar a interface do Ludo (Tabela 1) quanto à completude de indicadores relacionados às dimensões: utilidade, usabilidade, encontrabilidade, credibilidade, acessibilidade e desejabilidade propostos na colmeia de UX (Morville, 2004). Os indicadores de cada dimensão referem-se às recomendações de Acessibilidade Web Cognitiva que devem ser seguidas em propostas de desenvolvimento de interfaces para pessoas com TEA.

A avaliação inicial, realizada por uma das pesquisadoras especialista em alfabetização de autista, permitiu evidenciar os aspectos da UX a serem melhorados na interface do Ludo e com isso a nova interface foi projetada. Após a reformulação da interface, a especialista de dominio utilizou o mesmo checklist para avaliar o atendimento dos aspectos das dimensões da UX. Observa-se na última coluna da Tabela 1, que a interface ainda carece de melhorias, o que será realizada em nova versão de interface do Ludo. No entanto, os resultados da pesquisa experimental, realizada via teste de usabilidade, diretamente com as crianças, demonstram que a interface adaptada possibilitou que todas as atividades fossem realizadas pelas crianças. Isto mostra a boa aceitação das crianças na nova versão do jogo. Outro aspecto positivo foi o tempo de percepção para a realização das tarefas, os resultados obtidos são expressivos quando comparados com o tempo de percepção na interface original do jogo, conforme apresentado nas Tabelas 9 a 11 .

Apesar da impossibilidade de uma criança participar dos testes por problemas técnicos, relacionado ao hardware (ausência de tela touch screen no laboratório de Informática), o objetivo principal foi atingido e pretende-se dar sequência na pesquisa, com a inserção de novas fases no jogo realizadas com a coparticipação das mães e das crianças. 
Conclui-se que esta pesquisa, além de colaborar com a inclusão digital de crianças com TEA, possui um cárater inovador, pois o personagem principal do jogo foi criado com a coparticipação das crianças. Com base nos dados coletados idealizou-se o boneco físico (personagem principal) que foi associado ao jogo e disponibilizado virtualmente via interface do Ludo. A pretensão era envolver as crianças no projeto, em especial na criação dos bonecos e permitir que elas pudessem fazer associação (lembrar) do mesmo ao usar o jogo, bem como sentirem-se partícipes do processo. Contudo, as análises são insuficientes para sustentar tais hipóteses. Neste caso, há a necessidade de novas observações e envolvimento das crianças em outras funcionalidades do projeto.

\section{Referências}

AMERICAN PSYCHIATRIC ASSOCIATION (APA) (2014). Manual Diagnóstico e Estatístico de Transtornos Mentais: DSM-5. 5a . Edição, Porto Alegre: Artmed.

Avila, B. G., Passerino, L. M., \& Reategui, E. (2012). Proposta de uma metodologia para a construção de um sistema de CAA focado no contexto de seus usuários. Rev Bras Inform Educ, 20(1), 87-96. DOI: http://dx.doi.org/10.5753/rbie.2012.20.1.97. [GS Search].

Avila, B. G., Passerino, L. M., \& Tarouco, L. M. R. (2013). Usabilidade em tecnologia assistiva: estudo de caso num sistema de comunicação alternativa para crianças com autismo. RELATEC: Revista Latinoamericana de Tecnología Educativa, 12(2), 115-129. [GS Search].

Bernardino, L. M. F. (2015). A importância da escrita na clínica do autismo. Estilos da clínica. Revista sobre a infância com problemas, 20(3), 504-519. DOI: https://doi.org/10.11606/issn.1981-1624.v20i3p504-519. [GS Search].

Brasil, Ministério da Educação (2008). Política Nacional de Educação Especial na Perspectiva da Educação Inclusiva. Brasília: Ministério da Educação.

Britto, T. C. P. (2016). Recomendações do GAIA. Retrieved June 1, 2018. From http://talitapagani.com/gaia.

Brande, C. A., \& Zanfelice, C. C. (2012). A inclusão escolar de um aluno com autismo: diferentes tempos de escuta, intervenção e aprendizagens. Revista Educação Especial, 25(42), 43-56. DOI: http://dx.doi.org/10.5902/1984686X3350. [GS Search].

de Araújo, A. L. S. O., de Brito, R. R., \& da Silva, A. P. (2013). Softwares para educação inclusiva: uma revisão sistemática no contexto de SBIE e WIE. In Brazilian Symposium on Computers in Education (Simpósio Brasileiro de Informática na Educação-SBIE) (Vol. 24, No. 1, p. 507). [GS Search].

de Souza Bittencourt, I. G., \& Fumes, N. D. L. F. (2017). A tecnologia assistiva scala como recurso para produção de narrativas e registro de dados nas pesquisas em educação: uma experiência com pessoas adultas com transtorno do espectro autista. Revista IberoAmericana de Estudos em Educação, 12(esp.), 1481-1495. DOI: http://dx.doi.org/10.21723/riaee.v12.n.esp.2.1304. [GS Search].

Dias, C. (2003). Usabilidade na WEB - Criando portais mais acessíveis. Rio de Janeiro: Editora Alta Books Ltda. 296p.

Faria, K. T., Teixeira, M. C. T. V., Carreiro, L. R. R., Amoroso, V., \& de Paula, C. S. (2018). Atitudes e práticas pedagógicas de inclusão para o aluno com autismo. Revista Educação Especial, 31(61), 353-370. [GS Search]. 
Ferraz, R., \& Bechara, E. (2014). Diretrizes de Acessibilidade para Conteúdo Web (WCAG) 2.0. Retrieved August 3, 2016. From https://www.w3.org/Translations/WCAG20-pt-br/.

Francisco, D. J., \& da Silva, A. P. L. (2015). CRIANÇA E APROPRIAÇÃO TECNOLÓGICA: UM ESTUDO DE CASO MEDIADO PELO USO DO COMPUTADOR E DO TABLET. HOLOS, 6, 277-296. DOI: https://doi.org/10.15628/holos.2015.2702. [GS Search].

Gonçalves, A. G., Picharillo, A. D. M., \& Pedrino, M. C. (2017). Uso de objeto educacional digital na perspectiva da educação especial: relato de uma prática pedagógica. Revista on line de Política e Gestão Educacional, 1726-1735. DOI: https://doi.org/10.22633/rpge.v21.n.esp3.2017.10051. [GS Search].

Lindenmeyer, S., Schmidt, M., Matias, F., \& Rosangela Bez, M. (2016). " SE É PARA UM É PARA TODOS!" As potencialidades de um aluno evidenciadas através da comunicação alternativa com a utilização dos softwares Arasaac e Scala. Revista Vínculos, 13(2). [GS Search].

Mallmann, Angela Patrícia. Jogos Educacionais no Processo de Alfabetização. (2017). 27 f. Monografia (Especialização) - Curso de Tecnologias da Informação e da Comunicação Aplicadas à Educação, Artes e Letras, Universidade Federal de Santa Maria, Santa Maria, 2017. [GS Search].

Melo, A., \& Abelheira, R. (2015). Design Thinking \& Thinking Design: Metodologia, ferramentas e uma reflexão sobre o tema. Editora Novatec, 208p.

Nicolás, F. T. (2004). Tecnologías de Ayuda en Personas com Trastornos del Espectro Autista: Guía para Docentes. Edita: CPR Murcia I. Imprime: Pictografía, S.L. Depósito Legal: MU1020. ISBN: 84-688-6391-2.

Nielsen, J. (2000). Projetando Websites. 5. ed. Rio de Janeiro: Editora Campus, 416p.

Nielsen J., \& Loranger, H. (2007). Usabilidade na WEB. Editora Elsevier Brasil, 406p.

Norman, D. (2017). The Definition of User Experience (UX). Retrieved September 10, 2017. From https://www.nngroup.com/articles/definition-user-experience/.

Morville, P. (2004). User Experience Design. Retrieved June 2, 2017. From http://semanticstudios.com/user_experience_design/.

Pagani Britto, T. C., \& Brigante Pizzolato, E. (2018). GAIA: uma proposta de um guia de recomendações de acessibilidade de interfaces Web com foco em aspectos do Autismo. Revista Brasileira de Informática na Educação, 26(2).10. DOI: http://dx.doi.org/10.5753/rbie.2018.26.02.102. [GS Search].

Prensky, M. (2001). Digital natives, digital immigrants. De On the Horizon. NCB University Press, Vol. 9 No. 5.

Rodriguez, J. P. C., \& Pico, L. E. A. (2016). Un análisis del autismo desde la perspectiva de su influencia en familias y la tecnología como facilitador en el manejo de esta condición. Revista Logos, Ciencia \& Tecnología, 8(1), 168-182. [GS Search].

Seeman, L., \& Cooper, M. (2018a). Cognitive Accessibility User Research. Retrieved October 12, 2018. [GS Search].

Seeman, Lisa., \& Cooper, M. (2018b). Cognitive Accessibility Roadmap and Gap Analysis. Retrieved October 12, 2018. [GS Search].

Stickdorn, M., \& Schneider, J. (2014). Isto é Design Thinking de Serviços. 5. ed. Rio de Janeiro: Editora Bookman, 380p.

Teixeira, F. (2014). Introdução e boas práticas em UX Design. Editora Casa do Código. 
WebAIM (2014). Evaluating Cognitive Web Accessibility with WAVE. Retrieved October 10, 2018. From http://wave.webaim.org/cognitive. 